$\because \quad \because \quad \dot{t}$

Institute for Space Studies

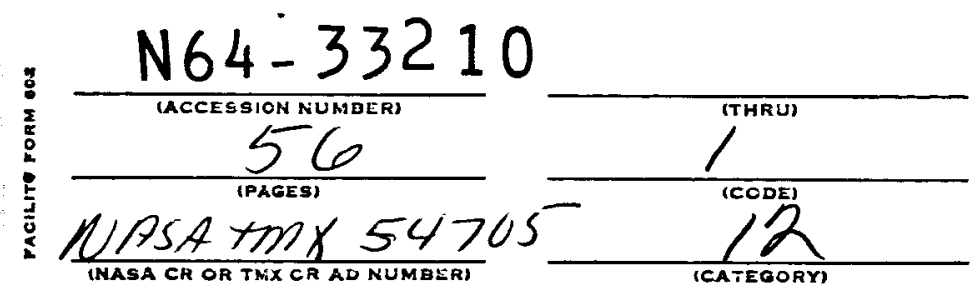

THE RED LINE OF ATOMIC OXYGEN

IN THE DAY AIRGLOW

A. Dalgarno

James C. G. Walker

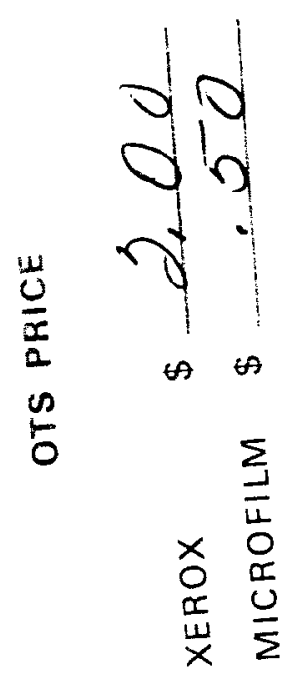

GODDARD SPACE FLIGHT CENTER

NATIONAL AERONAUTICS AND SPACE ADMINISTRATION 
THE RED LINE OF ATOMIC OXYGEN

IN THE DAY AIRGLOW

A. Dalgarno and James C.G. Walker

Queens University, Belfast, Northern

Ireland, and Goddard Institute for

Space Studies, New York 27, N. Y.

June, 1964

To be published in Journal of the Atmospheric Sciences 


\title{
THE RED LINE OF ATOMIC OXYGEN \\ IN THE DAY AIRGLOW
}

A. Dalgarno and James C. G. Walker

\begin{abstract}
Queens University, Belfast, Northern Ireland, and Goddard Institute for Space Studies, New York 27, N. Y.
\end{abstract}




\section{ABSTRACT}

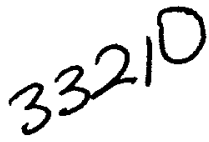

It is argued from the observations of the red line that the rate coefficient for deactivation of the excited oxygen atoms in collisions with molecular oxygen cannot be much less than $10^{-10} \mathrm{~cm}^{3} \mathrm{sec}^{-1}$ and that the solar flux in the region of $1450 \AA$ cannot be as large as the reported measured values. It is further argued that photodissociation of molecular oxygen and recombination of molecular ions are inadequate to explain the observations and that an additional mechanism is operative at high altitudes. The mechanisms of fluorescent excitation and of non-thermal excitation by photoelectrons are briefly examined and it is concluded that although the latter may be a significant source of excited atoms, neither mechanism explains the observed variability. It is suggested that the variability in red line intensities is associated with the presence of hot thermal electrons and sample calculations are presented of the altitude profiles that nay result from this source.

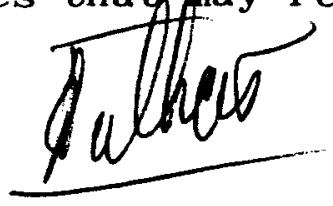




\section{Introduction}

From a theoretical survey, Bates and Dalgarno (1954) concluded that the red line of atomic oxygen at $6300 \AA$ is one of the strongest features of the dayglow spectrum, and a more quantitative study of the red line by Brandt (1958) yielded an intensity of 50 kilorayleighs (kR), about half arising from photodissociation of molecular oxygen in the Schumann-Runge continuum

$$
0_{2}+h \nu \rightarrow o\left({ }^{3} P\right)+o\left({ }^{1} D\right)
$$

and about half arising from dissociative recombination of the molecular ions $0_{2}^{+}$

$$
\mathrm{O}_{2}{ }^{+}+\mathrm{e} \rightarrow \mathrm{O}\left({ }^{1} \mathrm{D}\right)+\mathrm{o}^{\prime}
$$

The ground-based measurements of the red line in the dayglow by Noxon and Goody (1962) and by Jarrett and Hoey (1963) yielded intensities comparable with those predicted by Brandt, but other ground-based measurements by Noxon (1963) and rocket-based measurements by Zipf and Fastie (1963) and by Wallace and Nidey (1964) have shown that the intensity of the red line is often much less than the predicted value. This variation in intensity is significant for it suggests that the mechanisms leading to the emission of the red line have not been correctly identified and described. 


\section{Mode1 atmospheres}

To describe the structure of the neutral component of the upper atmosphere, we have employed the analytic representation of Bates (1959) which is specified by the temperature, temperature gradient and composition at a reference altitude, $z_{0}$, and by the exospheric temperature, $T(\infty)$. For the atmospheric parameters, we adopted the values

$$
\mathbf{z}_{\mathrm{o}}=120 \mathrm{~km},\left.\quad \frac{\mathrm{dT}}{\mathrm{dz}}\right|_{\mathrm{z}_{\mathrm{o}}}=20 \mathrm{~K} / \mathrm{km}, \quad \mathrm{T}\left(\mathrm{z}_{\mathrm{o}}\right)=350 \mathrm{~K}
$$

and for the number densities of atomic oxygen, molecular oxygen, and molecular nitrogen at $120 \mathrm{~km}$ the alternative sets (i) $\mathrm{n}(0)=5 \times 10^{10} \mathrm{~cm}^{-3}, \mathrm{n}\left(\mathrm{O}_{2}\right)=1 \times 10^{11} \mathrm{~cm}^{-3}, \mathrm{n}\left(\mathrm{N}_{2}\right)=5 \times 10^{11} \mathrm{~cm}^{-3}$, which we shall describe as the high $0_{2}$ atmosphere, and (ii) $\mathrm{n}(0)=5 \times 10^{11} \mathrm{~cm}^{-3}, \mathrm{n}\left(\mathrm{O}_{2}\right)=2 \times 10^{10} \mathrm{~cm}^{-3}, \mathrm{n}\left(\mathrm{N}_{2}\right)=5 \times 10^{11} \mathrm{~cm}^{-3}$, which we shall describe as the low $0_{2}$ atmosphere. The models appear to span the possible atmospheres (Nicolet, 1961; Harris and Priester, 1962; Pokhunkov, 1963; Jursa, Nakamura and Tanaka, 1963; Schaefer, 1963; Ha11, Schweizer, and Hinteregger, 1963; Nier, Hoffman, Johnson, and Holmes, 1964). The mass density distribution corresponding to the low $0_{2}$ atmosphere with $\mathrm{T}(\infty)=750 \mathrm{~K}$ and to high $0_{2}$ atmospheres with $\mathrm{T}(\infty)=750 \mathrm{~K}$ and $1000 \mathrm{~K}$ are compared in Fig. 1 with the density distributions derived from satellite drag data 
(King-Hele, 1963; Jacchia and Slowey, 1964; Bryant, 1964). The red line observations that we shall discuss were carried out in 1962 and 1963 and except when otherwise noted our results refer to the low $0_{2}$ atmosphere with $T(\infty)=750 \mathrm{~K}$, an atmosphere in harmony with the drag data and an atmosphere more easily reconciled with observations of the red line than are the high $0_{2}$ atmospheres. The number density, temperature, and mass density distributions corresponding to the low $0_{2}$ atmosphere with $T(\infty)=750 \mathrm{~K}$ are presented in Table 1 .

At altitudes below $120 \mathrm{~km}$ we used an atmosphere similar to the model of Jastrow and Kyle (1961).

3. Photodissociation in the Schumann-Runge continuum At wavelengths between $1350 \AA$ and $1750 \AA$, ultraviolet radiation is strongly absorbed in the Schumann-Runge continuum of molecular oxygen

$$
\mathrm{o}_{2}\left(\mathrm{x}^{3} \Sigma_{g}^{-}\right)+\mathrm{h} \nu \rightarrow \mathrm{o}_{2}\left(\mathrm{~B}^{3} \Sigma_{\mu}^{-}\right) \rightarrow o\left({ }^{3} \mathrm{P}\right)+\mathrm{o}\left({ }^{1} \mathrm{D}\right),
$$

the process providing a substantial source of $O\left({ }^{1} D\right)$ atoms in the upper atmosphere (Bates, 1948). The rate of production of $O\left({ }^{1} D\right)$ atoms at an altitude, $z$, and for a solar zenith angle, $\theta$, is given by

$$
Q_{1}(z, \theta)=n\left(0_{2} \mid z\right) \int_{1350}^{1750} F_{\infty}(\lambda) \sigma(\lambda) \exp [-\mu(\lambda)] d \lambda
$$




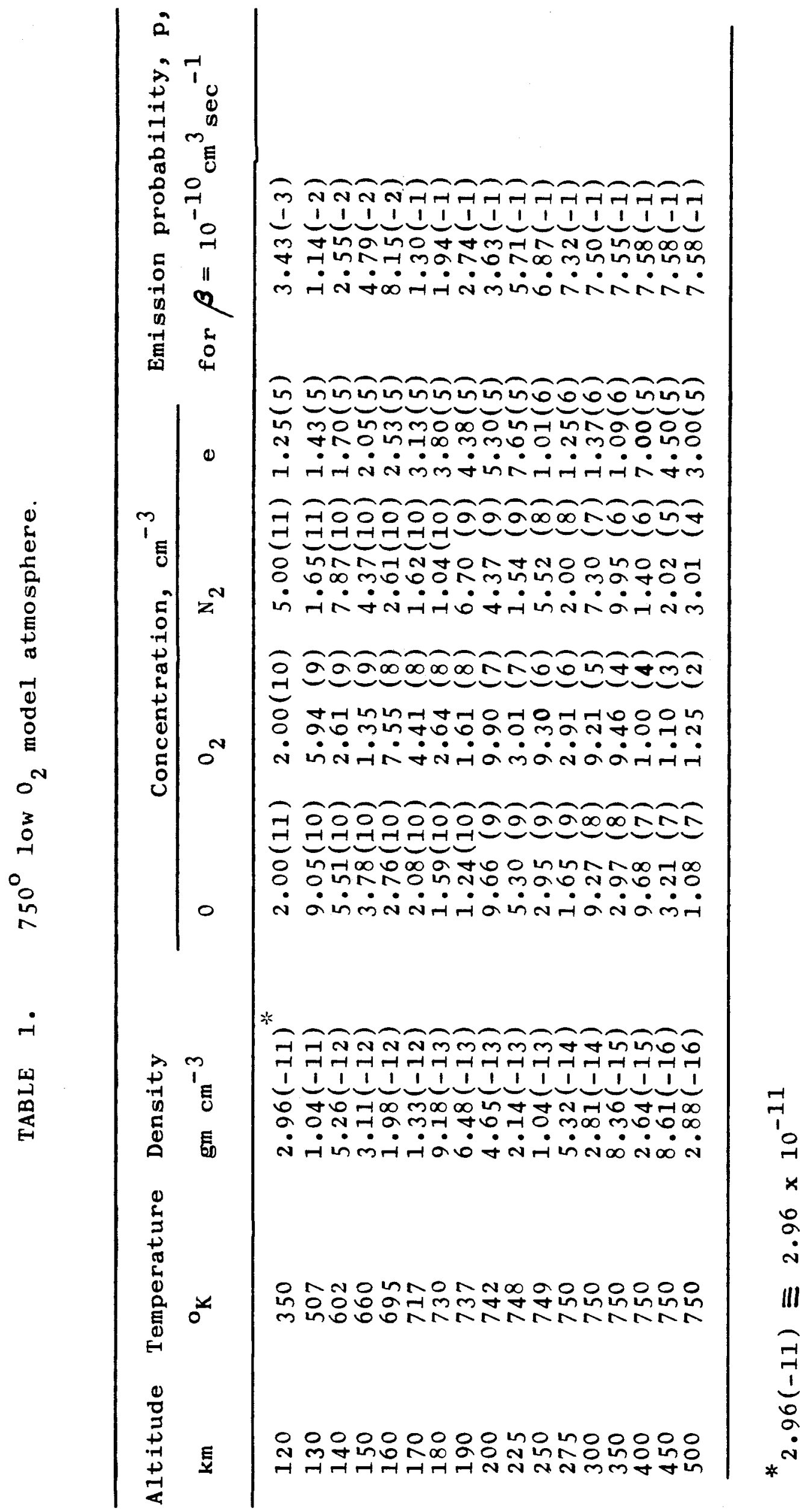


where $F_{\infty}(\lambda)$ is the incident flux, $\sigma(\lambda)$ is the absorption cross section and $\mu$ is the attenuation factor, $\mu(\lambda)=\sigma(\lambda) \int_{(R+z) \cos \theta}^{\infty} n\left(0_{2} \mid\left\{y^{2}+(R+z)^{2} \sin ^{2} \theta\right\}^{\frac{1}{2}}\right) d y$,

$R$ being the radius of the Earth. For the calculation of $Q_{1}$ we have used the measurements of $\sigma(\lambda)$ by Metzger and Cook (1964) and we have supposed the solar ultraviolet flux to be that of a black body at a temperature, $\mathrm{T}_{\mathrm{s}}$. The 1 imited data (Purcel1, Packer and Tousey, 1960; Detwiler, Garrett, Purcel1, and Tousey, 1961; Tousey, 1963) are consistent with a value of $4750 \mathrm{~K}$ for $\mathrm{T}_{\mathrm{s}}$. The results shown in Figs. 2 to 5 are actually appropriate to a solar temperature of $4500 \mathrm{~K}$, but they may all be scaled to a temperature of $4750 \mathrm{~K}$ by multiplying by a factor of 2.9 , the loss of accuracy being negligible.

Values of the production rates of $O\left({ }^{1} D\right)$ atoms are shown in Fig. 2 for several values of $\theta$. Since the intensity of the red line at $63000^{\circ}$ in the night airs low is much less than that of the green 1 ine at $5577 \AA$ (cf. Chamberlain, 1961a) and since the red line is emitted at a much greater altitude than is the green line (Packer, 1961; Tarasova, 1963), it is clear that severe deactivation of the $O\left({ }^{1} D\right)$ atoms must occur at the lower altitudes (Bates and Dalgarno, 1953; Seaton, 1954). Deactivation by electron impact is negligible 
(cf. Bates, 1960), and Bates and Dalgarno (1953) and Seaton (1958) have argued that the deactivation probably occurs in collisions with molecular oxygen. With this assumption, Wallace and Chamberlain (1959) have derived from an analysis of auroral observations of the $0_{2}$ atmospheric band system a rate coefficient, $\beta$, such that

$$
4 \times 10^{-12} \mathrm{~cm}^{3} \sec ^{-1}<\beta<10^{-10} \mathrm{~cm}^{3} \sec ^{-1} \text {. }
$$

Despite the fact that the mechanism does not conserve spin, it has been suggested that deactivation of $O\left({ }^{1} D\right)$ by molecular nitrogen is comparable in efficiency (DeMore and Raper, 1964) and, although the arguments are not convincing, the possibility cannot be excluded. Because the $\mathrm{N}_{2}$ density profile closely parallels the $0_{2}$ density profile, the inclusion of $\mathrm{N}_{2}$ deactivation would involve no important modification of our subsequent arguments and we shall largely ignore it.

During the day, deactivation by electron impact is still negligible but there occurs the possibility that $O\left({ }^{1} D\right)$ atoms may be removed by resonance absorption of solar radiation.

There appears to be only one allowed transition, the wavelength of which coincides with a strong solar line, and that is the transition to the $O\left(2 \mathrm{p}^{3} 3 \mathrm{~s}^{1} \mathrm{D}\right)$ state at $1152 \mathrm{~A}$, the solar flux in $1152 \AA$ being about $10^{9}$ photons $\mathrm{cm}^{-2} \mathrm{sec}^{-1}$ 
(Hinteregger, 1961; Hinteregger and Watanabe, 1962). Despite the substantial flux and the wavelength coincidence, the mechanism can be discounted because the only allowed transition from the upper state returns the atom to the original. ${ }^{1}$ D state.

The probability that an $O\left({ }^{1} D\right)$ atom at altitude, $z$, will emit a $6300 \AA$ photon is given by

$$
\begin{aligned}
p(z) & =\left\{1+\frac{A_{6364}}{A_{6300}}+\frac{\beta_{n}\left(O_{2} \mid z\right)}{A_{6300}}\right\}^{-1} \\
& =\left\{1.32+1.45 \times 10^{2} \beta \mathrm{n}\left(0_{2} \mid z\right)\right\}^{-1}
\end{aligned}
$$

where $A_{\lambda}$ is the radiative transition probability for the line of wavelength $\lambda(\mathrm{cf}$. Chamberlain, 1961b). Values of $p(z)$ are given in Table 1 for $\beta=10^{-10} \mathrm{~cm}^{3} \mathrm{sec}^{-1}$.

The intensities of red line emission for a solar temperature of $4500 \mathrm{~K}$ and various values of the deactivation coefficient, $\beta$, are shown in Fig. 3 as a function of solar zenith angle. The intensity for an overhead sun varies from $433 \mathrm{kR}$ in the absence of deactivation to $1.2 \mathrm{kR}$ if $\beta$ has a value of $10^{-10} \mathrm{~cm}^{3} \mathrm{sec}^{-1}$, which is close to the maximum possible for a thermal collision. Fig. 3 includes also the intensities corresponding to two other model atmospheres to show the lack of sensitivity to the details of the number density 
distribution.

To determine $\beta$ we note that Noxon (1963) has reported that the intensity of the dayglow red line at noon at fort Churchill was less than $2 \mathrm{kR}$ on December 15, 1962, a result in harmony with an observation of Wallace and Nidey (1964). Since Noxon was observing with the sun at a zenith angle of about $80^{\circ}$, it follows from Fig. 3 that, for the low $\mathrm{O}_{2}$ atmosphere with $\mathrm{T}(\infty)=750 \mathrm{~K}, \beta \geqslant 1.7 \times 10^{-10} \mathrm{~cm}^{3} \mathrm{sec}^{-1}$ if $\mathrm{T}_{\mathrm{S}}=4750 \mathrm{~K}$ and that $\beta \geqslant 3.7 \times 10^{-11} \mathrm{~cm}^{3} \mathrm{sec}^{-1}$ if $\mathrm{T}_{\mathrm{S}}=4500 \mathrm{~K}$. If deactivation in collisions with $\mathrm{N}_{2}$ were significant, the implied upper limit on $\mathrm{T}_{\mathrm{s}}$ would be increased.

Bates and Dalgarno (1954) pointed out that photodissociation in the Hartley continuum of ozone is an intense source of $O\left({ }^{1} D\right)$ atoms below $100 \mathrm{~km}$, and Cadle (1964) has predicted an intensity of $2 \mathrm{k} R$ for the resulting red 1 ine emission, his calculations following Brandt (1958) in using a value of $10^{-12} \mathrm{~cm}^{3} \mathrm{sec}^{-1}$ for $\beta$. With either of the two limits derived from Noxon's observations, the actual red line emission below $100 \mathrm{~km}$ must be negligible.

Adopting a value of $10^{-10} \mathrm{~cm}^{3} \sec ^{-1}$ for $\beta$, we show in Figs. 4 and 5, respectively, the emission rate and zenith intensity as functions of altitude for a number of solar zenith angles. 


\section{Ionic recombination}

There is usually a good correlation between the nocturnal intensity of the red line and the critical frequency of the F region (Barbier, 1957; Barbier and Glaume, 1962; Barbier, Roach, and Steiger, 1962; Carman and Kilfoyle, 1963; Barbier, 1964), supporting the beilef that the main excitation mechanism is dissociative recombination. Originally the molecular ion involved was identified as $0_{2}^{+}$but it is apparently now believed that $\mathrm{NO}^{+}$is the major participant (cf. Wallace and Nidey, 1964). The proposed reaction

$$
\mathrm{NO}^{+}\left(\mathrm{X}^{1} \Sigma^{+}\right)+\mathrm{e} \rightarrow \mathrm{N}\left({ }^{4} \mathrm{~S}\right)+\mathrm{O}\left({ }^{1} \mathrm{D}\right)
$$

fails to conserve spin. We therefore concentrate on $\mathrm{O}_{2}^{+}$ recombination as a source of $O\left({ }^{1} D\right)$ atoms. The ionospheric and airglow data presented by Barbier (1964) indicate that the rate of electron removal in the nocturnal ionosphere exceeds the rate of emission of $6300 \AA$ photons by a factor of about 8 , consistent with our suggestion that (7) is not an important mechanism for $0\left({ }^{1} D\right)$ excitation.

The nocturnal intensity of the red line is between 50R and 100R (cf. Chamberlain, 1961a) and considerable daytime enhancement is to be expected. The calculations by Brandt (1958) were based upon a simple sequence of ion-removal reactions and his results were sensitive to the adopted reaction rates. It is now clear that the actual reaction 
paths in the ionosphere are much more complicated (Nicolet and Swider, 1963; Dalgarno, 1964a). Serious uncertainties remain, the consequences of which can be largely avoided by assuming that local equilibrium prevails between ion production and removal rates, an assumption which is valid below $300 \mathrm{~km}$ throughout most of the day but fails at greater altitudes because of the increasing importance of diffusion. The ion production rates, $\mathrm{q}\left(\mathrm{O}^{+}\right), \mathrm{q}\left(\mathrm{N}_{2}^{+}\right)$, and $\mathrm{q}^{+}\left(\mathrm{O}_{2}^{+}\right)$ $\mathrm{cm}^{-3} \mathrm{sec}^{-1}$ have been calculated for a wide range of model atmospheres and solar zenith angles by Dalgarno and McElroy (1964a) and some of their results are reproduced in Fig. 6 . In order to estimate what fractions of the ions, $0^{+}$, $\mathrm{N}_{2}^{+}$, and $\mathrm{o}_{2}^{+}$, lead to $\mathrm{o}\left({ }^{1} \mathrm{D}\right)$ atoms, it is necessary first to determine what fractions of the ions $0^{+}$and $\mathrm{N}_{2}^{+}$are converted to $\mathrm{O}_{2}^{+}$ions or possibly to ${ }^{+}$ions. The fractions depend upon the electron density distribution and we have adopted the distribution measured by Brace, Spencer, and Carignan (1963) in a quiet ionosphere and included in Table 1. The intensity of the red line is insensitive to the details of the adopted electron density profile.

The reactions which remove $\mathrm{N}_{2}^{+}$ions have been discussed by Nicolet and Swider (1963). They are

$$
\mathrm{N}_{2}^{+}+\mathrm{e} \longrightarrow \mathrm{N}^{\prime}+\mathrm{N}^{\prime \prime}
$$




$$
\begin{aligned}
& \mathrm{N}_{2}^{+}+\mathrm{O}_{2} \rightarrow \mathrm{N}_{2}+\mathrm{O}_{2}^{+} \\
& \mathrm{N}_{2}^{+}+\mathrm{O} \longrightarrow \mathrm{N}_{2}+\mathrm{O}^{+} \\
& \mathrm{N}_{2}^{+}+\mathrm{O} \longrightarrow \mathrm{NO}^{+}+\mathrm{N}
\end{aligned}
$$

The rate coefficient of (8) has been measured as $2 \times 10^{-7} \mathrm{~cm}^{3}$ $\sec ^{-1}$ (cf. Biondi, 1964) and of (9) as $2 \times 10^{-10} \mathrm{~cm}^{3} \mathrm{sec}^{-1}$ (Fite, Rutherford, Snow, and van lint, 1962). Rate coefficients of $2 \times 10^{-11} \mathrm{~cm}^{3} \mathrm{sec}^{-1}$ for (10) and (11) have been derived by Norton, Van Zandt, and Denison (1963) and by Whitten and Poppoff (1964) from ionospheric data. The analyses of ionospheric data impose arbitrary temperature variations on the rates of the possible processes and the derived coefficients have little quantitative significance. However, the measured concentrations of $\mathrm{N}_{2}^{+}$apparently require that one or both of (10) and (11) be rapid so we assume that each of them has a rate coefficient of $1 \times 10^{-11} \mathrm{~cm}^{3} \mathrm{sec}^{-1}$. Since, in the atmosphere, (10) is usually followed by

$$
\mathrm{O}^{+}+\mathrm{N}_{2} \longrightarrow \mathrm{NO}^{+}+\mathrm{N}
$$

the distinction between (10) and (11) is unimportant for our purposes.

The $0^{+}$ions are removed by the ion-atom interchange reactions, (12) and

$$
\mathrm{o}^{+}+\mathrm{o}_{2} \rightarrow \mathrm{O}_{2}^{+}+\mathrm{o}
$$


(Bates, 1955). For our calculations we have adopted a rate coefficient of $1 \times 10^{-11} \mathrm{~cm}^{3} \mathrm{sec}^{-1}$ for both (12) and (13) (Sayers and Smith, 1964) but the red line intensity depends only upon the ratio of the rates of the two reactions.

The ion, $\mathrm{O}_{2}^{+}$, disappears by dissociative recombination

$$
\mathrm{O}_{2}{ }^{+}+\mathrm{e} \longrightarrow \mathrm{0}^{\prime}+0^{\prime \prime}
$$

throughout the altitude region in which (14) might provide a significant source of emission of the red line. Thus, if $f$ is the probability that (14) produces an $0\left({ }^{1} D\right)$ atom, the rate of production is given by

$$
\begin{aligned}
& e_{2}=f\left\{q\left(0_{2}{ }^{+}\right)+q\left(N_{2}{ }^{+}\right)\left[\alpha_{q}\left(0_{2}\right)\right.\right.
\end{aligned}
$$

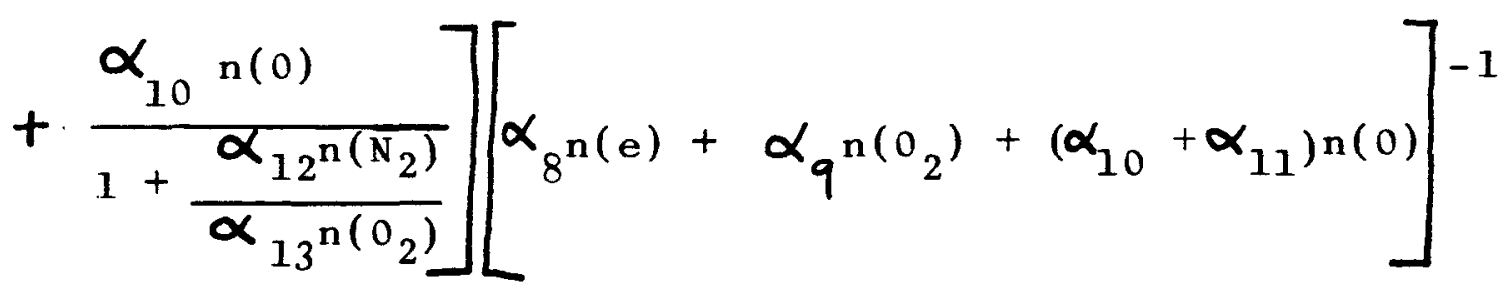

$$
\begin{aligned}
& \left.+q\left(0^{+}\right)\left[1+\frac{\alpha_{12}{ }^{n\left(N_{2}\right)}}{\alpha_{13}{ }^{n\left(0_{2}\right)}}\right]^{-1}\right\}
\end{aligned}
$$

The reaction is energetically capable of producing two $O\left({ }^{1} \mathrm{D}\right)$ atoms so that $f$ may be as large as 2 . In Fig. $7, Q_{2}(z)$ is 
shown as a function of altitude for several solar zenith angles with $f$ taken equal to 2 . The results provide an upper limit to the possible excitation rates consistent with the adopted ultraviolet flux and reaction rates.

Because $n\left(\mathrm{~N}_{2}\right)$ is much greater than $n\left(\mathrm{O}_{2}\right)$ in the altitude region where $\mathrm{q}\left(\mathrm{O}^{+}\right)$and $\left.\mathrm{q}_{2}{ }^{+}\right)$are comparable, the last term of (15) is important only at high altitudes where the production rates are sma11. Thus the intensity of the red line is insensitive to the magnitudes of $\alpha_{12}$ and $\alpha_{13}$ provided that $\alpha_{12}$ is not markedly smaller than $\alpha_{13^{*}}$. In contrast is the sensitivity to the relative values of $\alpha_{8}$ and $\alpha_{9}$. Reaction (9) is an important source of $\mathrm{O}_{2}{ }^{+}$ions at the lower altitudes where the production rates are large, whereas the sequence of (10) followed by (13) is important only at high altitudes where the production of $O\left({ }^{1} D\right)$ is small. Accordingly, we illustrate in Fig. 7 only the sensitivity to the ratio $\alpha_{8 /} \alpha_{9}$, the dashed curves of Fig. 7 arising when the value of $2 \times 10^{-10} \mathrm{~cm}^{3} \mathrm{sec}^{-1}$ for $\alpha_{9}$ is replaced by zero so that most of the $\mathrm{N}_{2}{ }^{+}$ions disappear by dissociative recombination.

The possible additional source of $O\left({ }^{1} D\right)$ atoms provided by the dissociative recombination of $\mathrm{NO}^{+}(7)$ is shown in Fig. 8 on the assumption that every $\mathrm{NO}^{+}$recombination yields an $O\left({ }^{1} \mathrm{D}\right)$ atom. The actual yield is presumably much less than unity. 
The rate of emission of $6300 \AA$ photons produced by dissociative recombination of $0_{2}{ }^{+}$with $\alpha_{8 / \alpha_{9}}=10^{3}, \alpha_{8 /} \alpha_{10}$ $=\alpha_{8 / \alpha_{11}}=2 \times 10^{4}, \alpha_{11 / \alpha_{12}}=1, \beta=10^{-10} \mathrm{~cm}^{3} \mathrm{sec}^{-1}$, and $\mathrm{f}=2$ is shown in Fig. 9. The corresponding zenith intensities are shown in Fig. 10.

Fig. 11 shows the sensitivity of the predicted intensities to the atmospheric model.

5. Photodissociation and ionic recombination

A comparison of Figs. 3 and 11 , and 5 and 10 shows that the contributions of photodissociation and of ionic recombination to the zenith intensity of the red line may be comparable, depending upon the values of $T_{s}$ and $f$, but there are significant differences in the variations with solar zenith angle and with altitude. The zenith intensity has been measured as a function of altitude by Zipf and Fastie (1963) at Wallops Island on May 7, 1964 with the sun at a zenith angle of $60^{\circ}$. We have attempted to reproduce the observational data of Zipf and Fastie by combining the contributions of photodissociation, shown in Fig. 5, and of ionic recombination, shown in Fig. 10, and regarding the 
solar temperature, $T_{S}$, and the excitation probability, $f$, as disposable parameters subject to $f \leqslant 2$.

Fig. 12 shows the best fits we have been able to obtain by this procedure for three model atmospheres. The results for the $1000^{\circ}$ high $0_{2}$ atmosphere with $T_{s}=4660$ and $f=2$ agree closely with the observations, the total zenith intensity being $4.8 \mathrm{kR}$ of which $3.1 \mathrm{kR}$ is due to photodissociation and $1.7 \mathrm{kR}$ to ionic recombination. The corresponding intensities appropriate to a zenith angle of $80^{\circ}$ are respectively $2.7 \mathrm{kR}$ and $1.0 \mathrm{kR}$, the sum of which exceeds the upper limit of 2 kR observed by Noxon (1963) at Fort Churchill at noon on December 15, 1962. In order to be consistent with an upper limit of $2 \mathrm{kR}$ at $80^{\circ}$, it is necessary with the $1000^{\circ}$ high $\mathrm{O}_{2}$ model atmosphere to adopt a solar temperature not greater than $4580 \mathrm{~K}$, even with $f=0$. The results for the other models shown in Fig. 12 lead to even greater conflict with Noxon's upper limit.

Temporal variations in the solar ultraviolet flux in the neighbourhood of $1216 \AA$ are small (Lindsay, 1963), and there is no evidence to suggest that large variations occur in the flux at the longer wavelengths of the Schumann-Runge continuum. Ignoring the possibility of temporal change in $\mathrm{T}_{S}$, we have determined the values of $\mathrm{T}_{S}$ which give the largest intensities at $60^{\circ}$ consistent with the upper limit of $2 \mathrm{kR}$ at $80^{\circ}$. The intensities as a function of altitude for the 
three model atmospheres are shown in Fig. 13. A11 of these models lead to intensities which are markedly lower than the Zipf and Fastie results. The situation cannot be improved by using lower values of $f$ and higher values of $T_{8}$ because, with a deactivation coefficient, $\beta$, of $10^{-10} \mathrm{~cm}^{3} \mathrm{sec}^{-1}$, the photodissociation contribution is nearly independent of $\theta$ as $\theta$ varies from $60^{\circ}$ to $80^{\circ}$.

There are also discrepancies in the detailed dependence of emission on altitude, Zipf and Fastie (1963) finding that the emission rate is $2.6 \times 10^{2} \mathrm{~cm}^{-3} \mathrm{sec}^{-1}$ from $120 \mathrm{~km}$ to $190 \mathrm{~km}$, increasing abrupt 1 y to $5.0 \times 10^{2} \mathrm{~cm}^{-3} \mathrm{sec}^{-1}$ from $190 \mathrm{~km}$ to $220 \mathrm{~km}$. The dependence of emission on altitude would be modified if the deactivation coefficient, $\beta$, were to change rapidly with increasing temperature. As Bates (1960) has pointed out, $O\left({ }^{1} D\right)$ atoms produced by dissociative recombination initial1y possess considerable kinetic energy so that the effective temperature controlling $\beta$ may be higher than the ambient temperature. The effect is probably small since molecular oxygen is a minor constituent at the altitudes of interest and thermalising collisions with the major constituents, 0 and $\mathrm{N}_{2}$, occur more frequently than deactivating collisions with $0_{2}$. A rapid change of $\beta$ with increasing altitude will not, in any case, remove the discrepancy between the predicted intensities of Fig. 13 and the observed intensities. The discrepancy can more plausibly be attributed to an additional 
excitation mechanism.

6. Fluorescent excitation

Bates (1948) and Chamberlain (1958) have shown that resonance scattering of sunlight

$$
O\left({ }^{3} \mathrm{P}\right)+\lambda 6300 \rightarrow O\left({ }^{1} \mathrm{D}\right)
$$

does not contribute significantly to the twilight glow in the red line and it follows from their calculations, but including deactivation, that the yield in the dayglow does not exceed 20R.

Fluorescence through the sequences

$$
\begin{aligned}
& o\left({ }^{3} \mathrm{P}\right)+\lambda 1304 \longrightarrow o\left({ }^{3} \mathrm{~S}\right) \\
& o\left({ }^{3} \mathrm{~S}\right) \longrightarrow O\left({ }^{1} \mathrm{D}\right)+\lambda_{1641}
\end{aligned}
$$

or

$$
O\left({ }^{3} \mathrm{~s}\right) \quad \longrightarrow \quad O\left({ }^{1} \mathrm{~s}\right)+\lambda 2325
$$

followed by

$$
O\left({ }^{1} \mathrm{~S}\right) \quad \longrightarrow \quad O\left({ }^{1} \mathrm{D}\right)+\lambda 5577
$$

may be a more abundant source of dayglow red line emission and incidentally of dayglow green line emission also, for the atmosphere is optically very thick in the triplet centered 
at $\lambda 1304$.

The intensity of $\lambda 1304$ has been measured by Donahue and Fastie (1964) and by Fastie, Crosswhite and Heath (1964). If we assume a Doppler width corresponding to a temperature in the region of $2000 \mathrm{~K}$ for the line and a value of $4.0 \mathrm{x}$ $10^{-6}$ (Garstang, 1961) for the ratio of the transition probabilities for the emission of $\lambda_{1641}$ and $\lambda_{1304}$ radiation, the measured intensities of $\lambda 1304$ lead to an estimate of the order of $100 \mathrm{R}$ for the red line, an estimate which is consistent with the fact that $\lambda 1641$ radiation has not been detected in the airglow. The contribution of (19) and (20) is much smaller because the ratio of the transition probabilities for the emission of $\lambda 2325$ and $\lambda 1304$ is $1.6 \mathrm{x}$ $10^{-8}$ (Garstang, 1961).

None of the mechanisms discussed so far explains the great variability of the red line intensity, discovered by Noxon (1964). The electron temperature is markedly higher than the neutral particle temperature in the $F$ region and may well be very variable (Spencer, Brace, and Carignan, 1962; Brace, Spencer, and Carignan, 1963; Nagy, Brace, Carignan, and Kanal, 1963) and the energy source responsible may also be a source of excitation of the red line.

\section{Electron impact excitation}

7.1 Thermal excitation. It has been pointed out (Dalgarno, 
1964b) that a rise in the temperature of the ambient electron gas will be accompanied by an enhancement of the red line. Spencer, Brace, and Carignan (1962) and Brace, Spencer, and Carignan (1963) have presented the results of measurements of electron densities and electron temperatures from several rocket flights. If we assume that there is no depletion of the high energy tail of the velocity distribution, the associated red line emission rates may be easily computed using rate coefficients derived from Seaton (1956). The emission rates and intensities as functions of altitude are shown in Figs. 14 and 15 for a deactivation coefficient $\beta=10^{-10}$ $\mathrm{cm}^{3} \mathrm{sec}^{-1}$.

In calculating the zenith intensities, it is necessary to estimate the emission at altitudes above those for which electron temperature and density data are available. We have assumed that the electron gas is isothermal and in diffusive equilibrium at these altitudes. The contribution of the high altitudes to the overhead intensity is about $30 \%$ for flight $6.02,20 \%$ for flight $6.01,5 \%$ for flight 6.03 , and $0.1 \%$ for flight 6.04 .

Flight 6.01 was fired from Fort Churchill on March 16, 1960, during spread $F$ conditions and flight 6.04 was fired from Wallops Island on March 3, 1961, during quiet ionospheric conditions. The red line intensities predicted for thermal excitation are $4.1 \mathrm{kR}$ and $0.79 \mathrm{kR}$ respectively. The altitude 
profiles are markedly different, the emission rate for flight 6.04 peaking at $220 \mathrm{~km}$ and decreasing rapidly and that for flight 6.01 varying little from $220 \mathrm{~km}$ up to at least $320 \mathrm{~km}$.

Flight 6.04 provides an interesting contrast to flight 6.02 which was fired from Fort Churchill on June 15, 1960, also during quiet ionospheric conditions. F1ight 6.02 is actually very similar to the spread F flight 6.01 with a predicted intensity of $4.9 \mathrm{k} R$ and an emission rate varying little from $225 \mathrm{~km}$ up to at least $280 \mathrm{~km}$.

Flight 6.03 was fired from Wallops Island on August 3, 1960, following a period of magnetic disturbance. Below $250 \mathrm{~km}$ the results are similar to those for the quiet ionosphere Wallops Island flight 6.04. However, the.6.03 emission rate is enhanced at greater altitudes, with a second maximum at $310 \mathrm{~km}$ and a relatively slow decrease above this altitude. The predicted intensity for flight 6.03 is $1.2 \mathrm{kR}$.

The day time electron temperature is very sensitive to smal1 disturbances and it appears that the intensity and the altitude dependence of the red line may be still more sensitive. Thus an increase in electron temperature of $10 \%$ during flight 6.04 would raise the predicted red line intensity from $0.79 \mathrm{kR}$ to $2.1 \mathrm{kR}$. The combined profile due to such arbitrary thermal excitation, to Schumann-Runge photodissociation with $T_{S}=4610 \mathrm{~K}$ and to ionic recombination with $f=2$ is in harmony with that observed by Zipf and Fastie (1963), as Fig. 16 
demonstrates. This model reconciles the observation of $\mathrm{Zipf}$ and Fastie with Noxon's (1963) upper limit on the intensity at Fort Churchill if we assume that electron impact excitation was negligible at the time of Noxon's measurement.

The very high intensities of the order of $40 \mathrm{kR}$ observed by Noxon and Goody (1962) and by Jarrett and Hoey (1963) can be ascribed to thermal excitation by electrons with a temperature in the region of $4000 \mathrm{~K}$. Such high temperatures have been detected, but only occasionally, on Explorer XVII (Brace and Spencer, 1964) and it is significant that very intense red line emission is also a rare phenomenon (Noxon, 1964).

The Explorer XVII data show an early morning maximum in the electron temperature (Brace and Spencer, 1964), related presumably to the dawn effect (Dalgarno and McElroy, 1964b), and an early morning enhancement of the red line may be a regular feature of itsdiurnal variation.

Satellite observations (Willmore, Henderson, Boyd, and Bowen, 1964; Brace and Spencer, 1964) show that the electron temperature remains higher than the neutral particle temperature during the night. The temperatures are usually too low to give rise to significant thermal excitation and the intensity associated with the nocturnal rocket flight 6.05 of Brace, Spencer, and Carignan (1963) was a fraction of a rayleigh. However the energy source associated with the heating of the electrons may contribute directly to excitation 
of the red line and it is interesting to note that Barbier (1964) has suggested that about $20 \mathrm{R}$ of red 1 ine emission is not directly correlated with the normal ionospheric parameters.

A similar effect may occur during the day.

7.2 Non-thermal excitation. A major source of heat during daylight is the fast photoelectrons produced by photoionization by solar ultraviolet radiation. The photoelectrons lose energy through a complicated sequence of collision processes, one of which is electron impact excitation of atomic oxygen to the $O\left({ }^{1} D\right)$ state (Hanson and Johnson, 1961; Hanson, 1963; Dalgarno, McElroy, and Moffett, 1963; Dalgarno, 1964b). The resulting altitude profile will be similar to that derived for thermal excitation and the intensity may be of the order of a kilorayleigh in which case the importance of thermal excitation in the interpretation (Fig. 16) of the observed profile (Zipf and Fastie, 1963 ) must be correspondingly diminished.

\section{Conclusions}

Noxon's observation that the intensity of the red line at a zenith angle of $80^{\circ}$ is less than $2 \mathrm{kR}$ places severe restrictions upon the contributions from photodissociation of molecular oxygen and from recombination of molecular ions. 
A part of this research was performed while walker was at Columbia University and was supported by the National Aeronautics and Space Administration under Grant Number NSG- 445 . 


\section{REFERENCES}

Barbier, D., 1957: La lumière du ciel nocturne en été a Tamanrasset. $\quad$ Compt $\cdot \underline{\text { Rend }}$., 245, 1559-1561.

Barbier, D., 1964: Nouvelles observations de la raie rouge du ciel nocturne en Afrique. Ann. Geophys., $\underline{20}, 22-33$

Barbier, D., and J. Glaume, 1962: La couche ionosphérique nocturne $F$ dans la zone intertropicale et ses relations avec l'emission de la raie $6300 \AA$ du ciel nocturne. Planetary Space Sci., 9, 133-148.

Barbier, D., F. E. Roach, and W. R. Steiger, 1962: The summer intensity variation of $[0 I] 6300 \AA$ in the tropics. I. Res. NBS, 66D (1), 145-152

Bates, D. R., 1948: Theoretical considerations regarding the night sky emission. Emission Spectra of Night Sky and Aurorae, London, Physical Society, 21-33. Bates, D. R., 1955: Charge transfer and ion-atom interchange collisions. Proc. Phys. Soc. London, A68, 344-345.

Bates, D. R., 1959: Some problems concerning the terrestrial atmosphere above about the $100 \mathrm{~km}$ 1evel. Proc. Roy. Soc. London, A253, 451-462.

Bates, D. R.; 1960: The airglow. Physics of the Upper Atmosphere, edited by J.A. Ratcliffe, New York, 


\section{REFERENCES -- Continued}

Academic Press, 219-267.

Bates, D. R., and A. Dalgarno, 1953: The altitudes of the luminous layers in the earth's atmosphere. J. Atmospheric Terrest. Phys., 4, 112-123.

Bates, D. R., and A. Dalgarno, 1954: Theoretical considerations regarding the dayglow. J. Atmospheric Terrest. Phys., 2, 329-344.

Biondi, M. A., 1964: Electron-ion and ion-ion recombination. Ann. Geophys., 20, 34-46.

Brace, L. H., and N. W. Spencer, 1964: to be published.

Brace, L. H., N. W. Spencer, and G. R. Carignan, 1963:

Ionosphere electron temperature measurements and their implications. J. Geophys.Res., 68, 5397-5412. Brandt, J. C., 1958: Oxygen red lines in the airglow. III.

The dayglow. Astrophys. J., 128, 718-723. Bryant, R., 1964: Densities obtained from drag on the Explorer 17 satellite. J. Geophys. Res., 69, 1423-1425. Cadle, R., 1964: Daytime atmospheric $O\left({ }^{1} D\right)$ : Discussions Faraday Soc., in press. Carman, E. H., and B. P. Kilfoyle, 1963: Relationship between [OI] $6300 \mathrm{~A}$ zenith airglow and ionospheric parameters $\underline{\mathrm{f}}_{\mathrm{O}} \underline{\mathrm{F}}_{2}$ and $\underline{\mathrm{h}} \underline{\mathrm{F}}$ at Townsville. $\underline{\mathrm{J}}$. Geophys. Res. , 68, 5605-5607. 
REFERENCES -- Continued

Chamberlain, J. W., 1958: Oxygen red lines in the airglow. I. Twilight and night excitation processes. Astrophys. J., $127,54-66$.

Chamberlain, J. W., 1961a: The energies in the spectra of the airglow and aurora. Ann. Geophys., 17, 90-99. Chamberlain, J. W., 1961b: Physics of the Aurora and Airglow. New York, Academic Press. Dalgarno, A., 1964a: Thermal reactions involving charged particles. Discussions Faraday Soc., in press. Dalgarno, A., 1964b: Corpuscular radiation in the upper atmosphere. Ann. Geophys., 20, 65-74. Dalgarno, A., and M. B. McElroy, 1964a: Electron and ion production rates in the upper atmosphere. To be published.

Dalgarno, A., and M. B. McElroy, 1964b: Electron temperatures at dawn. To be published.

Dalgarno, A., M. B. McElroy, and R. J. Moffett, 1963:

Electron temperatures in the ionosphere. Planetary Space Sci., 11, 463-484.

DeMore, W., and O. F. Raper, 1964: Deactivation of $O\left({ }^{1} \mathrm{D}\right)$ in the atmosphere. Astrophys. J., 139, in press. Detwiler, C. R., D. L. Garrett, J D. Purcell, and R. Tousey, 1961: The intensity distribution in the ultraviolet solar spectrum. Ann. Geophys., 17, 9-18. 


\section{REFERENCES -- Continued}

Donahue, T. M., and W. G. Fastie, 1964: Observation and interpretation of resonance scattering of Lyman $\alpha$ and $O I$ (1300) in the upper atmosphere. Space Research, 4, Amsterdam, North-Holland Publishing Company, in press.

Fastie, W. G., H. M. Crosswhite, and D. F. Heath, 1964: Rocket spectrophotometer airglow measurements in the far ultraviolet. I. Geophys. Res., 69, in press. Fite, W. L., J. A. Rutherford, W. R. Snow, and V. A. J. van Lint, 1962: Ion-neutral collisions in afterglow. Discussions Faraday Soc., 33, 264-272.

Garstang, R. H., 1961: Mutual magnetic interactions and oscillator strengths in the first spectrum of oxygen. Proc. Cambridge Phil. Soc., 27, 115-120.

Hall, L. A., W. Schweizer, and H. E. Hinteregger, 1963: Diurnal variation of the atmosphere around 190 kilometers derived from solar extreme ultraviolet absorption measurements. J. Geophys. Res., 68, 6413-6417.

Hanson, W. B., 1963: Electron temperatures in the upper atmosphere. Space Research, 3, edited by W. Priester, Amsterdam, North-Holland Publishing Company, 282-302. Hanson, W. B., and F. S. Johnson, 1961: Electron temperatures in the ionosphere. Mémoires Soc. ‥ Sc. Liège, Ser. 5, 4, 390-424. 


\section{REFERENCES -- Continued}

Harris, I., and W. Priester, 1962: Time-dependent structure of the upper atmosphere. J. Atmospheric Sci., 19, 286-301.

Hinteregger, H. E., 1961: Preliminary data on solar extreme ultraviolet radiation in the upper atmosphere. J. Geophys. Res., 66, 2367-2380.

Hinteregger, H. E., and K. Watanabe, 1962: Photoionization rates in the $\mathrm{E}$ and $\mathrm{F}$ regions, 2. J. Geophys. Res., 67, 3373-3392.

Jacchia, L. G., and J. Slowey, 1964: Atmospheric heating in the auroral zones: A preliminary analysis of the atmospheric drag of the Injun 3 satellite. J. Geophys. Res., 69, 905-910.

Jarrett, A. H., and M. J. Hoey, 1963: A ground-level photographic observation of the day airglow emission of atomic oxygen at $6300 \AA$. Planetary Space Sci., Il, 1251-1252.

Jastrow, R., and L. Kyle, 1961: The earth atmosphere. Handbook of Astronautical Engineering, edited by H. H. Koelle, New York, McGraw-Hill, Chapt. 2, 2-13. Jursa, A. S., M. Nakamura, and Y. Tanaka, 1963: Molecular oxygen distribution in the upper atmosphere. J. Geophys. Res., 68, 6145-6155. 


\section{REFERENCES -- Continued}

King-Hele, D. G., 1963: Decrease in upper atmosphere density since the sunspot maximum of 1957-58. Nature, 198, 832-834.

Lindsay, J. C., 1963: Scientific results of the first orbiting solar observatory. Trans. Am. Geophys. Union, 44, 722-725.

Metzger, P. H., and G. R. Cook, 1964: A reinvestigation of the absorption cross sections of molecular oxygen in the 1050 - $1800 \AA$ region. J. Quantitative Spectroscopy Radiative Transfer, 4; 107-116.

Nagy, A. F., L. H. Brace, G. R. Carignan, and M. Kanal, 1963: Direct measurements bearing on the extent of thermal nonequilibrium in the ionosphere. J. Geophys. Res., 68, 6401-6412.

Nicolet, M., 1961: Density of the heterosphere related to temperature. Res. in Space Sci., Smithsonian Inst. Astrophys. Observ., Spec. Rpt. 75. Nicolet, M., and W. Swider, 1963: Ionospheric conditions. Planetary Space Sci., 11, 1459-1482.

Nier, A. O., J. H. Hoffman, C. Y. Johnson, and J. C. Holmes, 1964: Neutral composition of the atmosphere in the 100-to 200-kilometer range. J. Geophys. Res., 69, 979-989.

Norton, R. B., T. E. Van Zandt, and J. S. Denison, 1963: 


\section{REFERENCES -- Continued}

A model of the atmosphere and ionosphere in the $E$ and FI regions. Proceedings International Conference on the Ionosphere, edited by A. C. Stickland, London, Institute of Physics and Physical Society, 26-34. Noxon, J. F., 1963: Observation of daytime aurora. J. Atmospheric Terrest. Phys., 25, 637-645. Noxon, J. F., 1964: A study of the 6300A oxygen line in the day airglow. $\mathrm{J}$. Geophys. Res., 69, in press. Noxon, J. F., and R. M. Goody, 1962: Observation of day airglow emission. I. Atmospheric Sci., 19, 342-343. Packer, D. M., 1961: Altitudes of the night airglow radiations. Ann. Geophys., 17, 67-74.

Pokhunkov, A. A., 1963: Gravitational separation, composition and structural parameters of the night atmosphere at altitudes between 100 and $210 \mathrm{~km}$. Planetary Space Sc1., 11, 441-449.

Purcell, J. D., D. M. Packer, and R. Tousey, 1960: The ultraviolet spectrum of the sun. Space Research, I, edited by H. K. Kallman-Bijl, Amsterdam, NorthHolland Publishing Company, 581-589. Sayers, J., and D. Smith, 1964: Ion and charge exchange reactions involving atmospheric gases. Discussions Faraday Soc., in press.

Schaefer, E. J., 1963: The dissociation of oxygen meas- 


\section{REFERENCES -- Continued}

ured by a rocket-borne mass spectrometer. J. Geophys. Res., 68, 1175-1176.

Seaton, M. J. 1954: Excitation processes in the aurora and airglow, 2. Excitation of forbidden atomic lines in high latitude aurorae. J. Atmospheric Terrest. Phys., 4, 295-313.

Seaton, M. J., 1956: The calculation of cross-sections for excitation of forbidden atomic lines by electron impact. The Airglow and the Aurorae, edited by

E. B. Armstrong and A. Dalgarno, London, Pergamon Press, 289-301.

Seaton, M. J., 1958: 0xygen red lines in the airglow. II. Collisional deactivation effects. Astrophys. J., 127, 67-74.

Spencer, N. W., L. H. Brace, and G. R. Carignan, 1962:

Electron temperature evidence for nonthermal equilibrium in the ionosphere. J. Geophys. Res., 67, $157-175$.

Tarasova, T. M., 1963: Night-sky emission-line intensity distribution with respect to height. Space Research, 2, edited by W. Priester, Amsterdam, North-Holland Publishing Company, 162-172. Tousey, R., 1963: The extreme ultraviolet spectrum of the sun. Space Science Reviews, $2,3-69$. 


\section{REFERENCES -- Continued}

Wallace, L., and J. W. Chamberlain, 1959: Excitation of $\mathrm{O}_{2}$ atmospheric bands in the aurora. Planetary space Sci., $\underline{2}, 60-70$.

Wallace, L., and R. A. Nidey, 1964: Measurement of the daytime airglow in the visual region. J. Geophys. Res., 69, 471-479.

Whitten, R. C., and I. G. Poppoff, 1964: Ion kinetics in the lower ionosphere. I. Atmospheric Sci., 2l, $117-133$.

Willmore, A. P., C. L. Henderson, R. L. F. Boyd, and P. J. Bowen, 1964: Electron temperature in the upper F-region. Proc. Roy. Soc. London, A, in press. Zipf, E. C., and W. G. Fastie, 1963: An observation of day airglow emission at 6300A. J. Geophys. Res., 68, 6208-6209. 


\section{FIGURE LEGENDS}

\section{Figure}

1. Comparison of the model atmospheres with mid-year daytime maximum satellite drag densities (King-Hele, 1963; Jacchia and Slowey, 1964; Bryant, 1964).

2. Dependence on altitude of the rate of production of $O\left({ }^{I} D\right)$ atoms by photodissociation of $\mathrm{O}_{2}$ for the $750^{\circ}$ low $\mathrm{O}_{2}$ model atmosphere with $\mathrm{T}_{\mathrm{S}}=4500 \mathrm{~K}$. Results are shown for several values of solar zenith angle, $\boldsymbol{\theta}$.

3. Dependence on solar zenith angle of the intensity which results from the photodissociation of $0_{2}$ with $\mathrm{T}_{\mathrm{s}}=4500 \mathrm{~K}$. Results are shown for several atmospheric models and several values of the deactivation coefficient, $\beta$. The upper limit imposed by Noxon's (1963) observation is indicated.

4. Dependence on altitude of the emission of $\lambda 6300$ which results from the photodissociation of $\mathrm{O}_{2}$. The results are for the $750^{\circ}$ low $0_{2}$ model atmosphere with $\mathrm{T}_{\mathrm{S}}=4500 \mathrm{~K}$ and $\boldsymbol{\beta}=10^{-10}$ $\mathrm{cm}^{3} \mathrm{sec}^{-1}$.

5. Dependence on altitude of the zenith intensity which results from the photodissociation of $\mathrm{O}_{2}$. The 
FIGURE LEGENDS -- Continued

Figure

results are for the $750^{\circ}$ low $\mathrm{O}_{2}$ model atmosphere with $\mathrm{T}_{\mathrm{S}}=4500 \mathrm{~K}$ and $\beta=10^{-10} \mathrm{~cm}^{3} \mathrm{sec}^{-1}$.

6. Dependence on altitude of the ion production rates for the $750^{\circ}$ low $\mathrm{O}_{2}$ model atmosphere.

7. Dependence on altitude of the rate of production of $O\left({ }^{l} D\right)$ atoms by the dissociative recombination of $\mathrm{O}_{2}{ }^{+}$for the $750^{\circ}$ Iow $\mathrm{O}_{2}$ model atmosphere.

8. Dependence on altitude of the rate of production of $O\left({ }^{I} D\right)$ atoms by the dissociative recombination of $\mathrm{NO}^{+}$for the $750^{\circ}$ low $\mathrm{O}_{2}$ model atmosphere.

9. Dependence on altitude of the emission of $\lambda 6300$ which results from the dissociative recombination of $\mathrm{O}_{2}^{+}$for the $750^{\circ}$ low $\mathrm{O}_{2}$ model atmosphere.

10. Dependence on altitude of the zenith intensity which results from the dissociative recombination of $\mathrm{O}_{2}^{+}$for the $750^{\circ}$ low $\mathrm{O}_{2}$ model atmosphere.

11. Dependence on solar zenith angle of the intensity which results from the dissociative recombination of $\mathrm{O}_{2}{ }^{+}$for several model atmospheres with $\beta=10^{-10} \mathrm{~cm}^{3} \mathrm{sec}^{-1}$ and $f=2$.

12. Comparison of the data of Zipf and Fastie (1963) with the theoretical intensities at $\boldsymbol{\theta}=60^{\circ}$ which

- result from photodissociation and ionic recom- 


\section{FIGURE LEGENDS -- Continued}

Figure

bination. All three models use $f=2$ and $\beta=$ $10^{-10} \mathrm{~cm}^{3} \mathrm{sec}^{-1}$.

13. Comparison of the data of Zipf and Fastie (1963) with theoretical intensities at $\theta=60^{\circ}$ due to photodissociation and ionic recombination for models which lead to an intensity of $2 \mathrm{kR}$ at

$$
\begin{aligned}
& \theta=80^{\circ} \text {. The calculations assume } \mathrm{f}=2 \text { and } \\
& \beta=10^{-10} \mathrm{~cm}^{3} \mathrm{sec}^{-1} \text {. }
\end{aligned}
$$

14. Dependence on altitude of the emission of $\lambda 6300$ which results from excitation by thermal electrons for four measured profiles of electron temperature and density (Spencer, Brace, and Carignan, 1962; Brace, Spencer, and Carignan, 1963). The results are for the $750^{\circ}$ low $\mathrm{O}_{2}$ model atmosphere with $\boldsymbol{\beta}=10^{-10} \mathrm{~cm}^{3} \mathrm{sec}^{-1}$.

15. Dependence on altitude of the zenith intensity which results from excitation by thermal electrons for four measured profiles of electron temperature and density (Spencer, Brace, and Carignan, 1962; Brace, Spencer, and Carignan, 1963). The results are for the $750^{\circ}$ low $\mathrm{O}_{2}$ model atmosphere with $\beta=10^{-10} \mathrm{~cm}^{3} \mathrm{sec}^{-1}$.

16. Comparison of the data of Zipf and Fastie (1963) with the theoretical intensity which results from 


\section{FIGURE LEGENDS -- Continued}

Figure

the combination of photodissociation with $\mathrm{T}_{\mathbf{S}}$

$=4610 \mathrm{~K}$, ionic recombination with $f=2$, and electron excitation given by the profile calculated for flight 6.04 enhanced by a factor of 2.7. The theoretical results are for the $750^{\circ}$ low $\mathrm{O}_{2}$ model atmosphere with $\beta=10^{-10} \mathrm{~cm}^{3} \mathrm{sec}^{-1}$. 


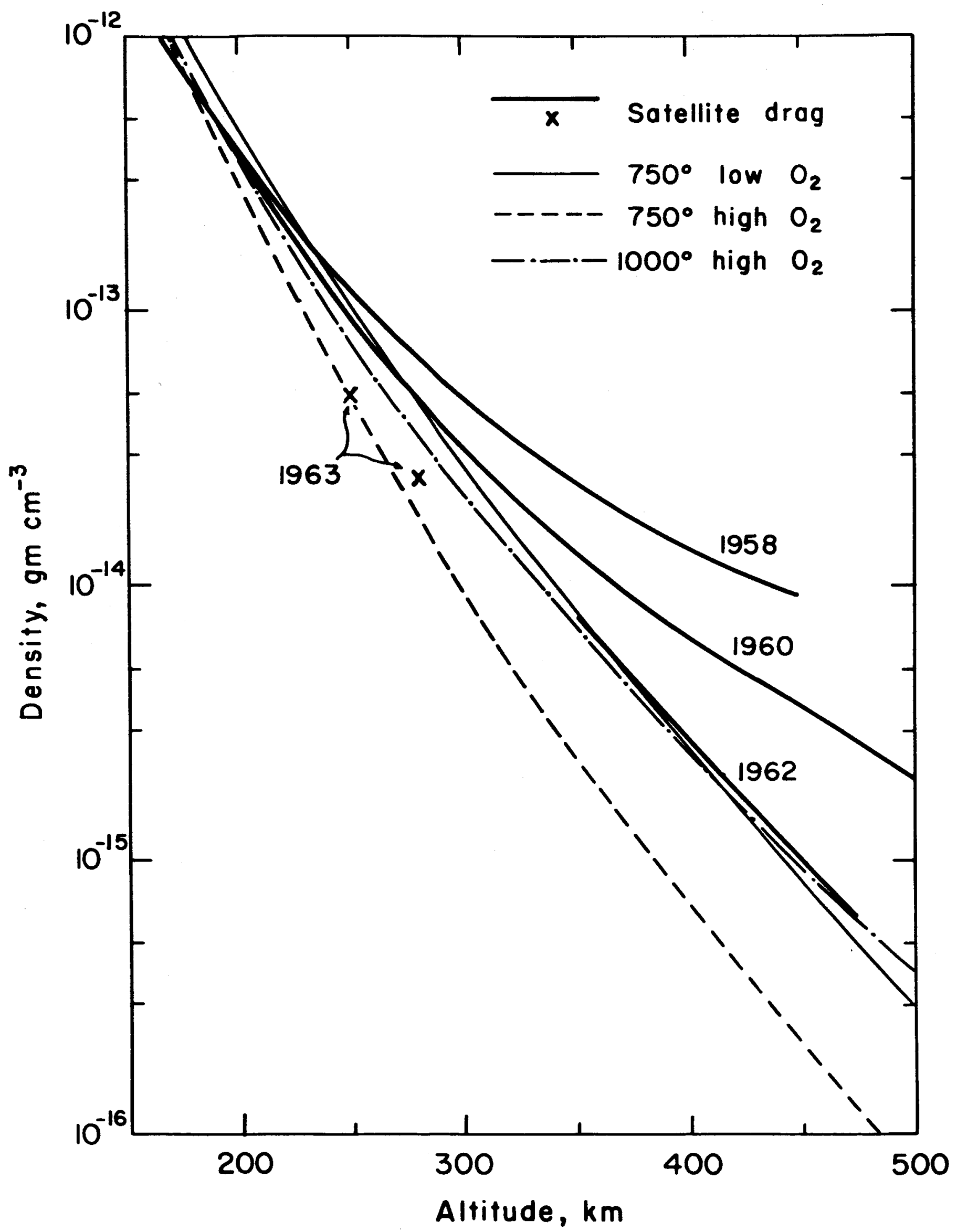

Fig. I 


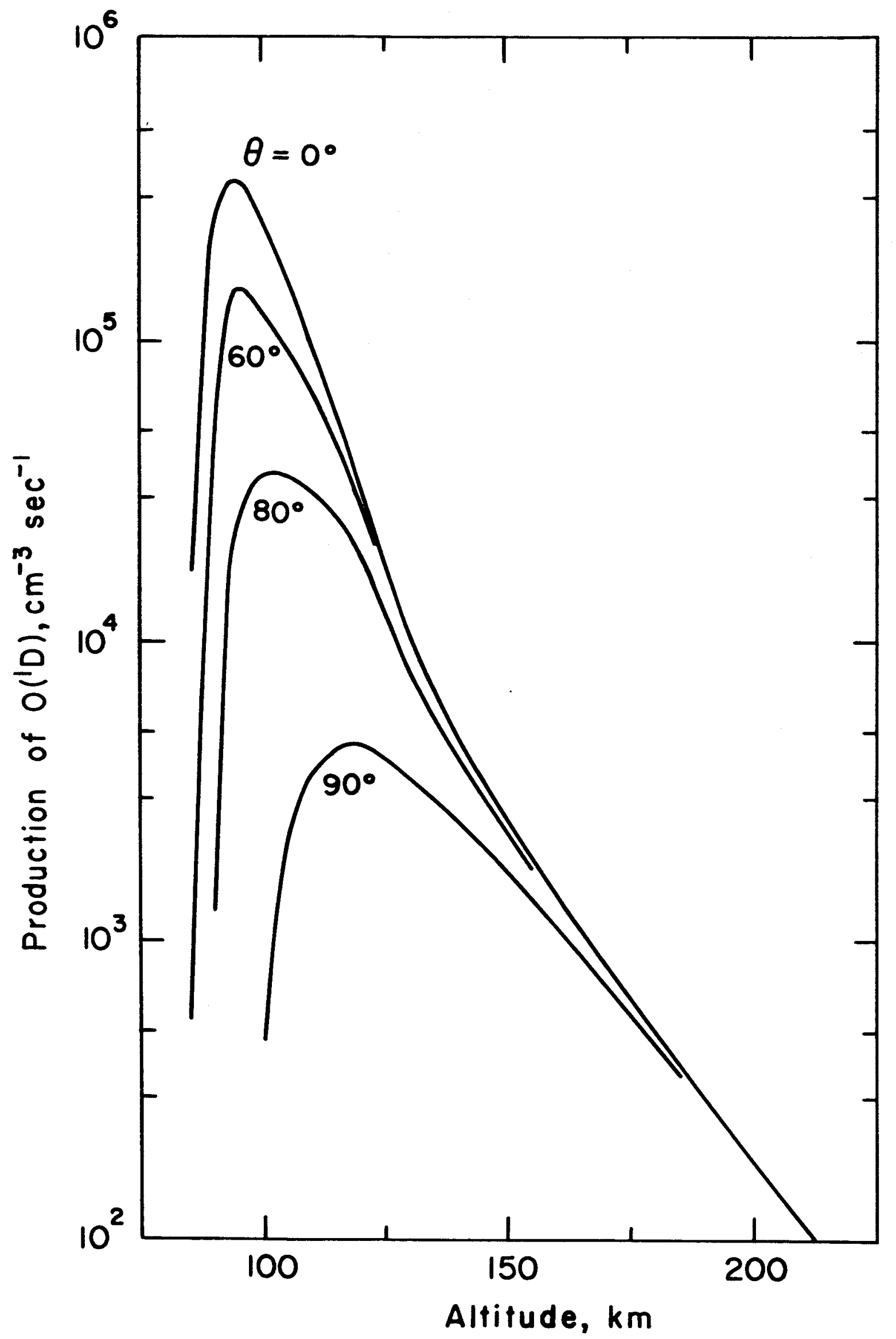

Fig. 2 


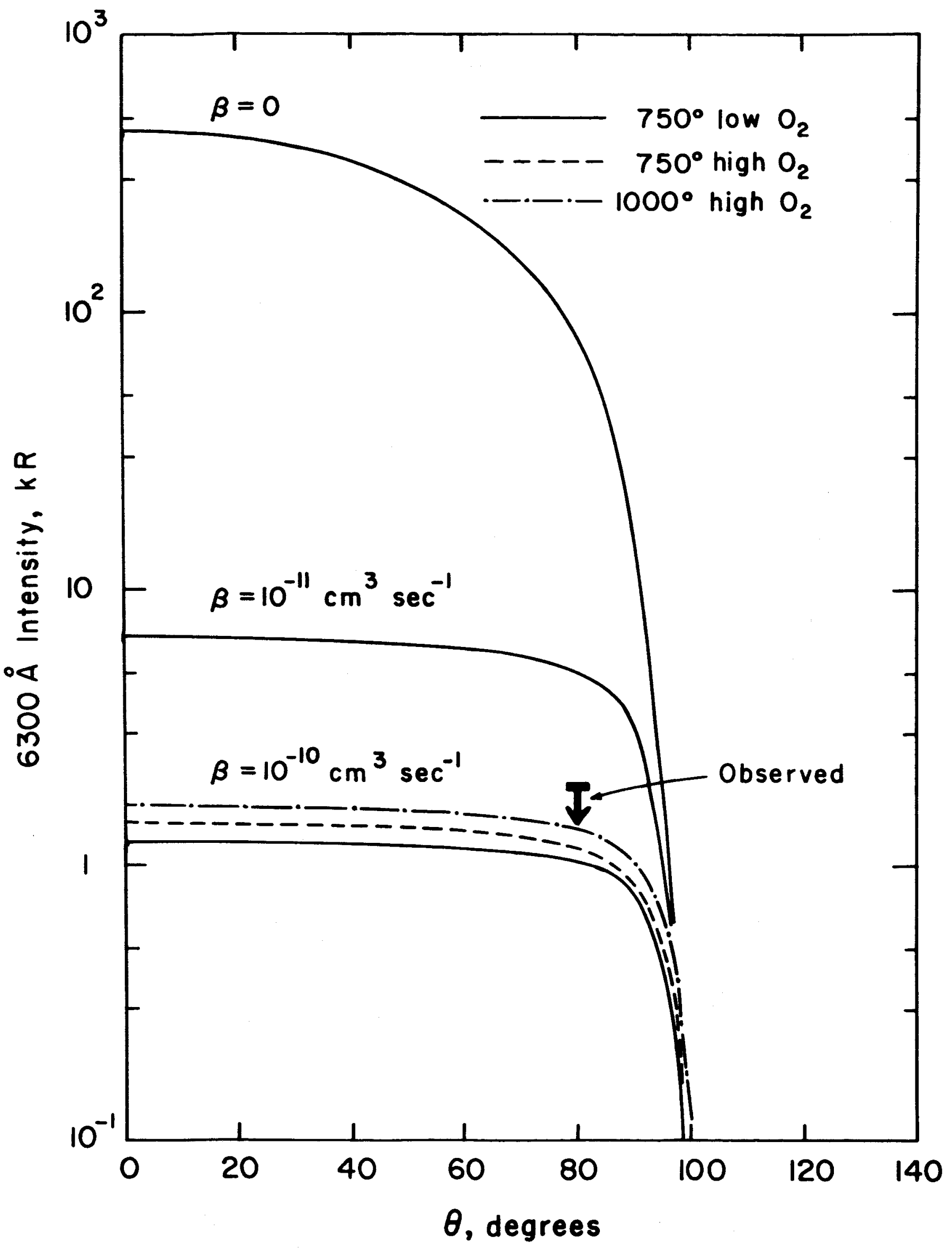

Fig. 3 


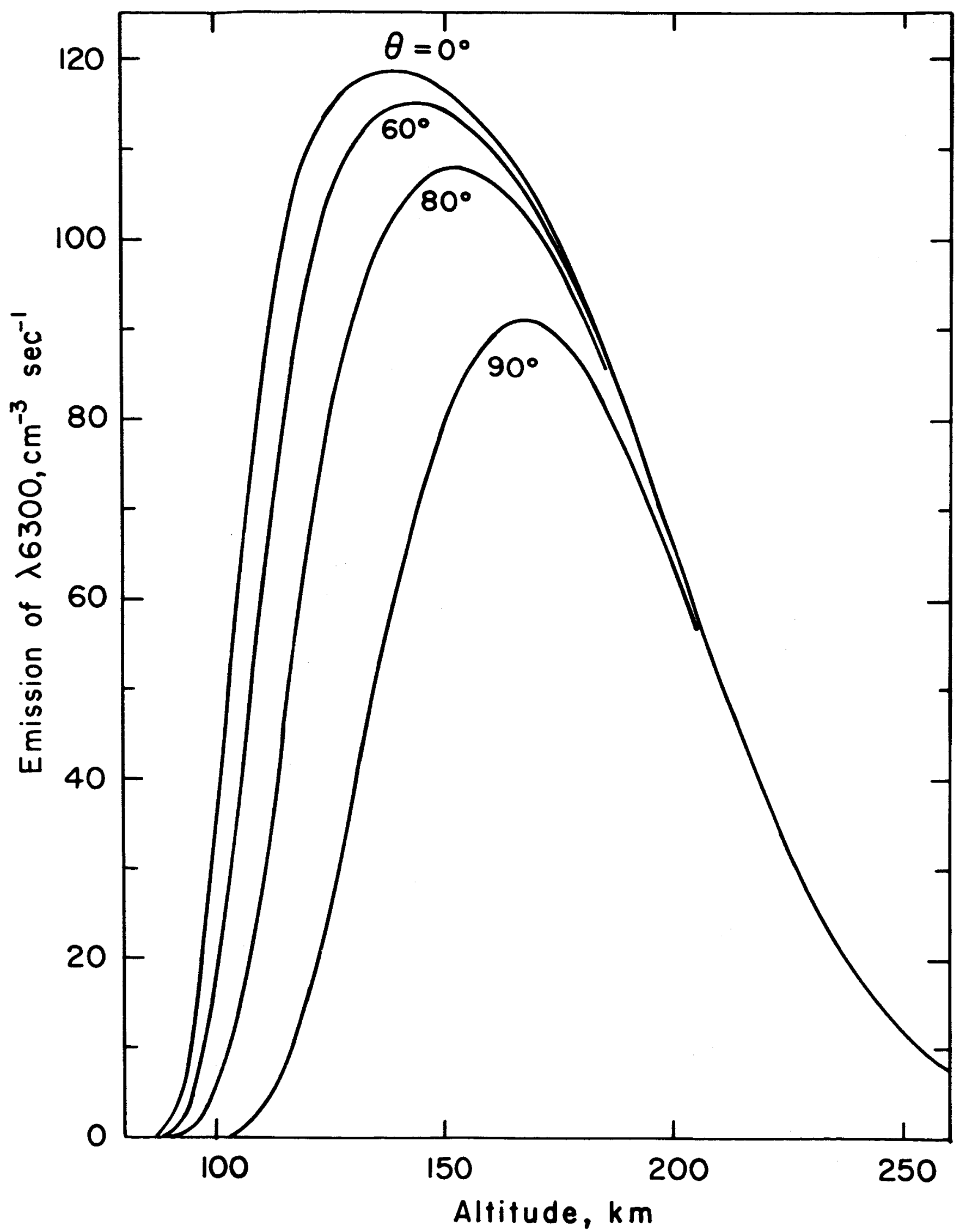

Fig. 4 


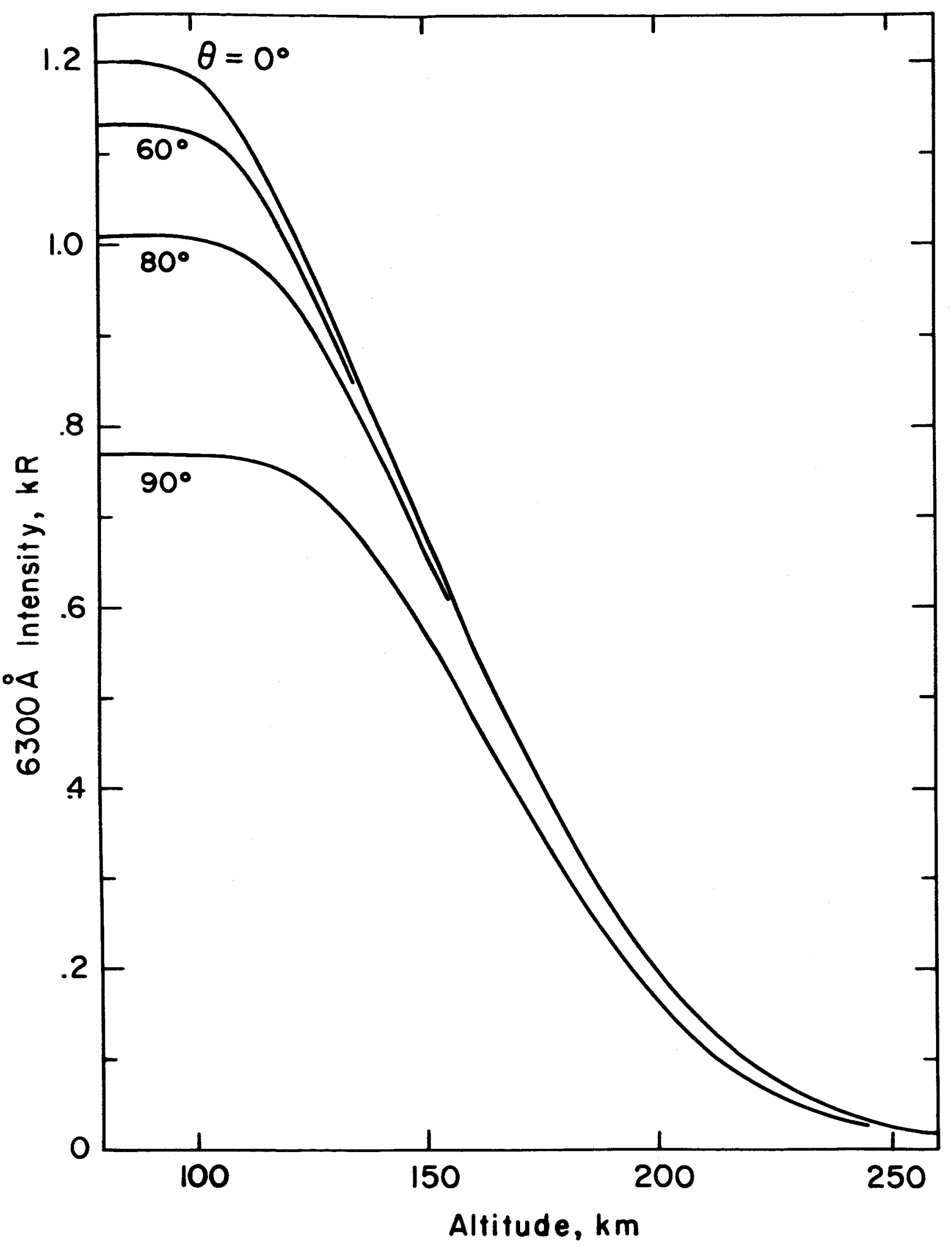

Fig. 5 


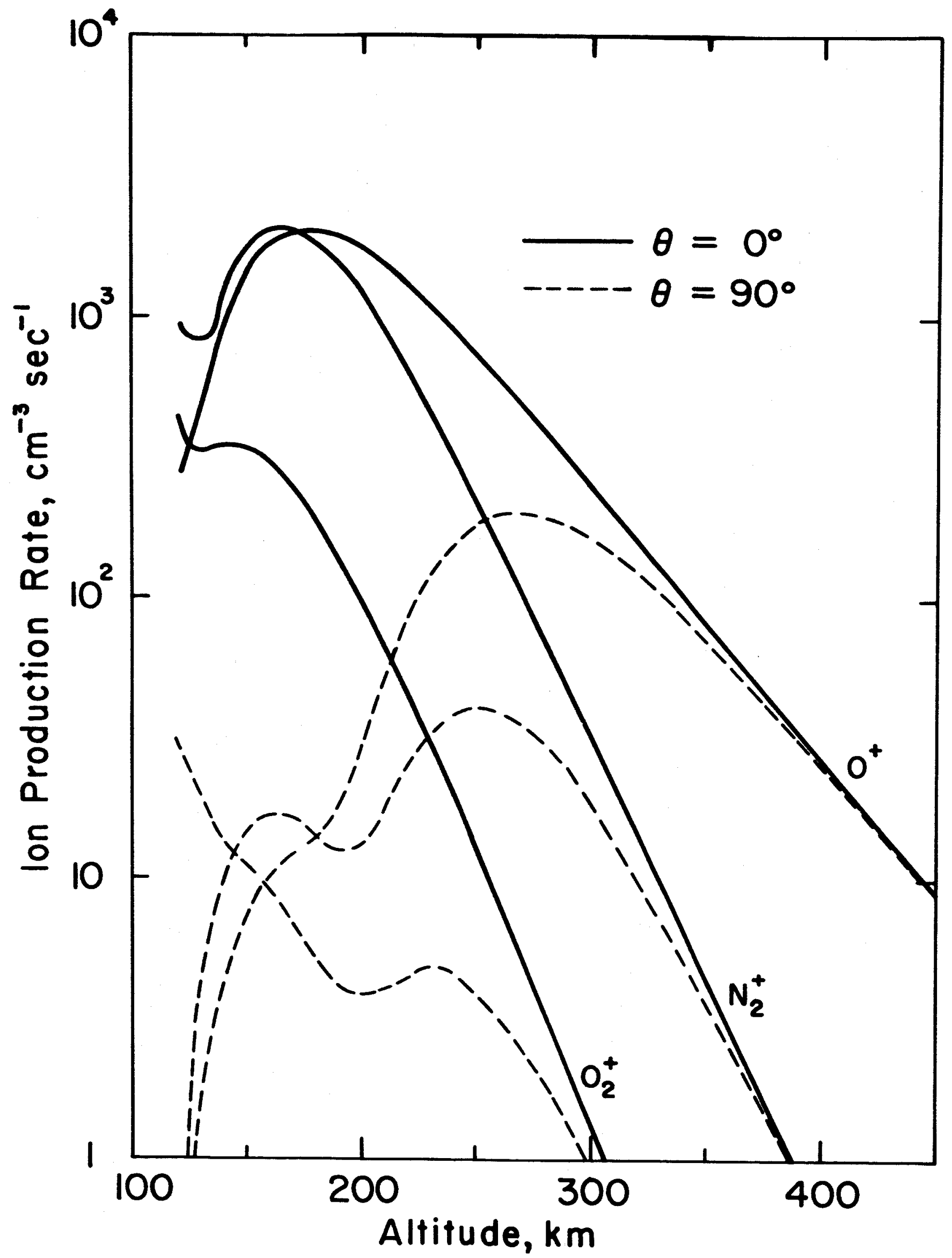

Fig. 6 


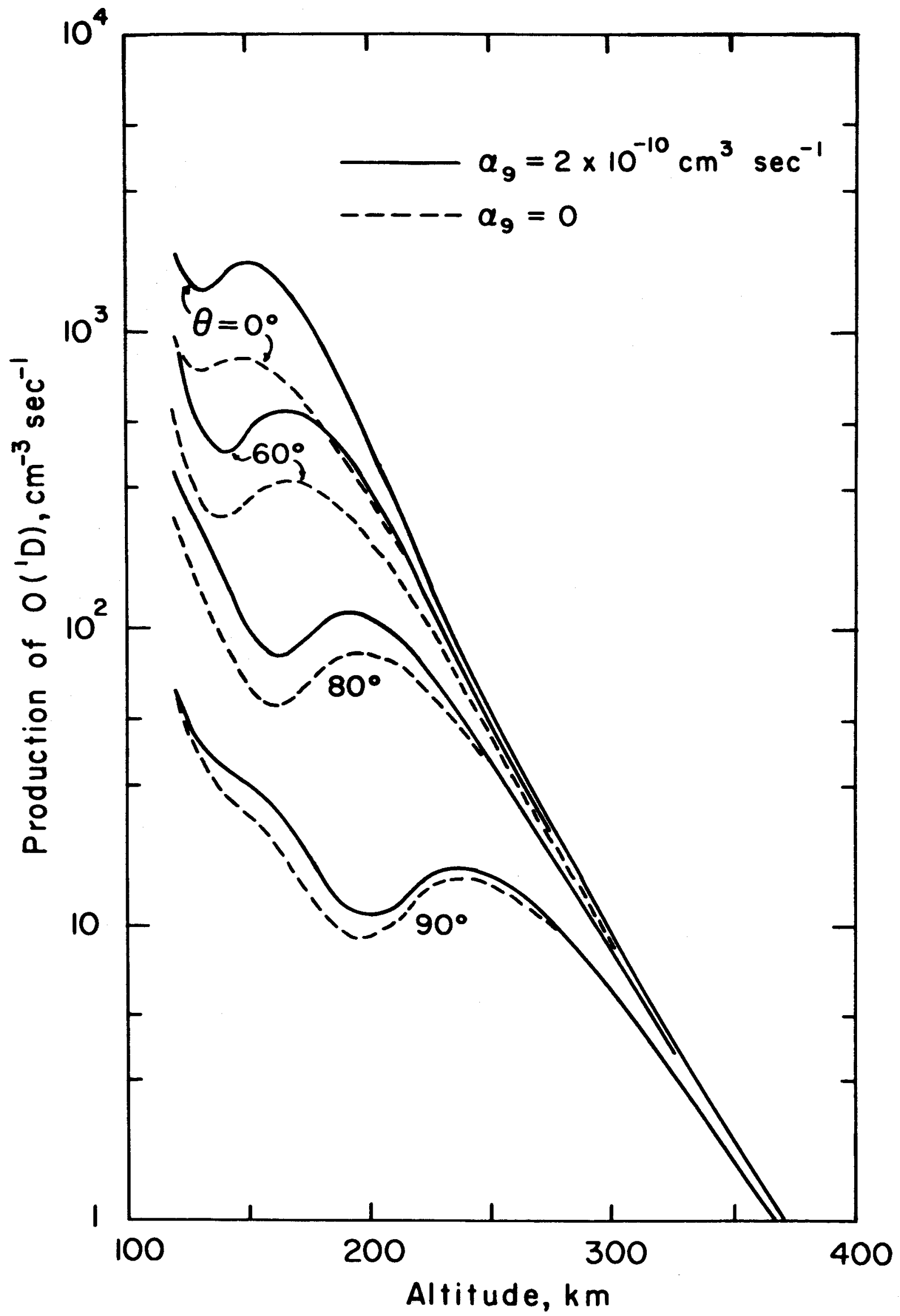

Fig. 7 


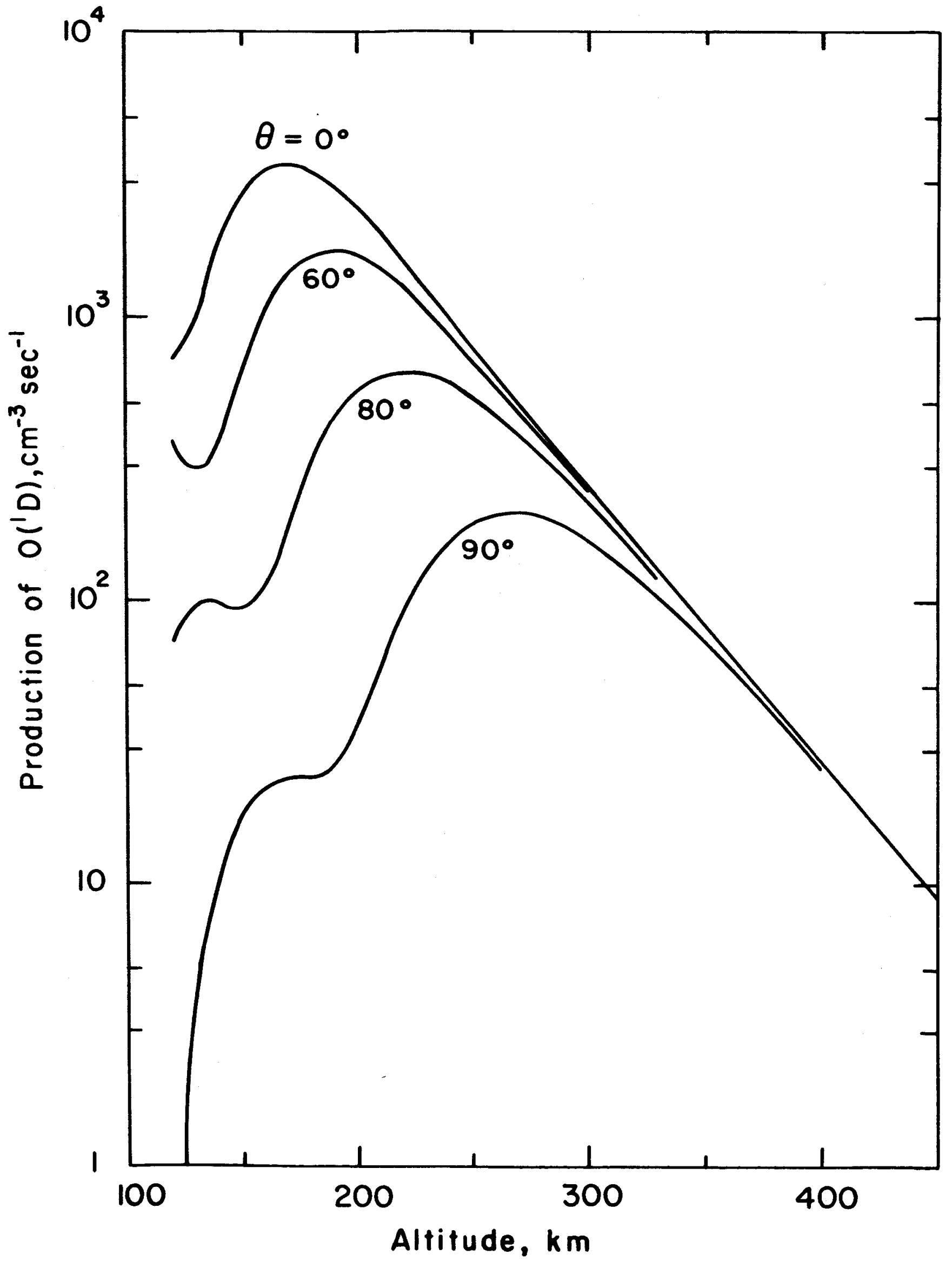

Fig. 8 


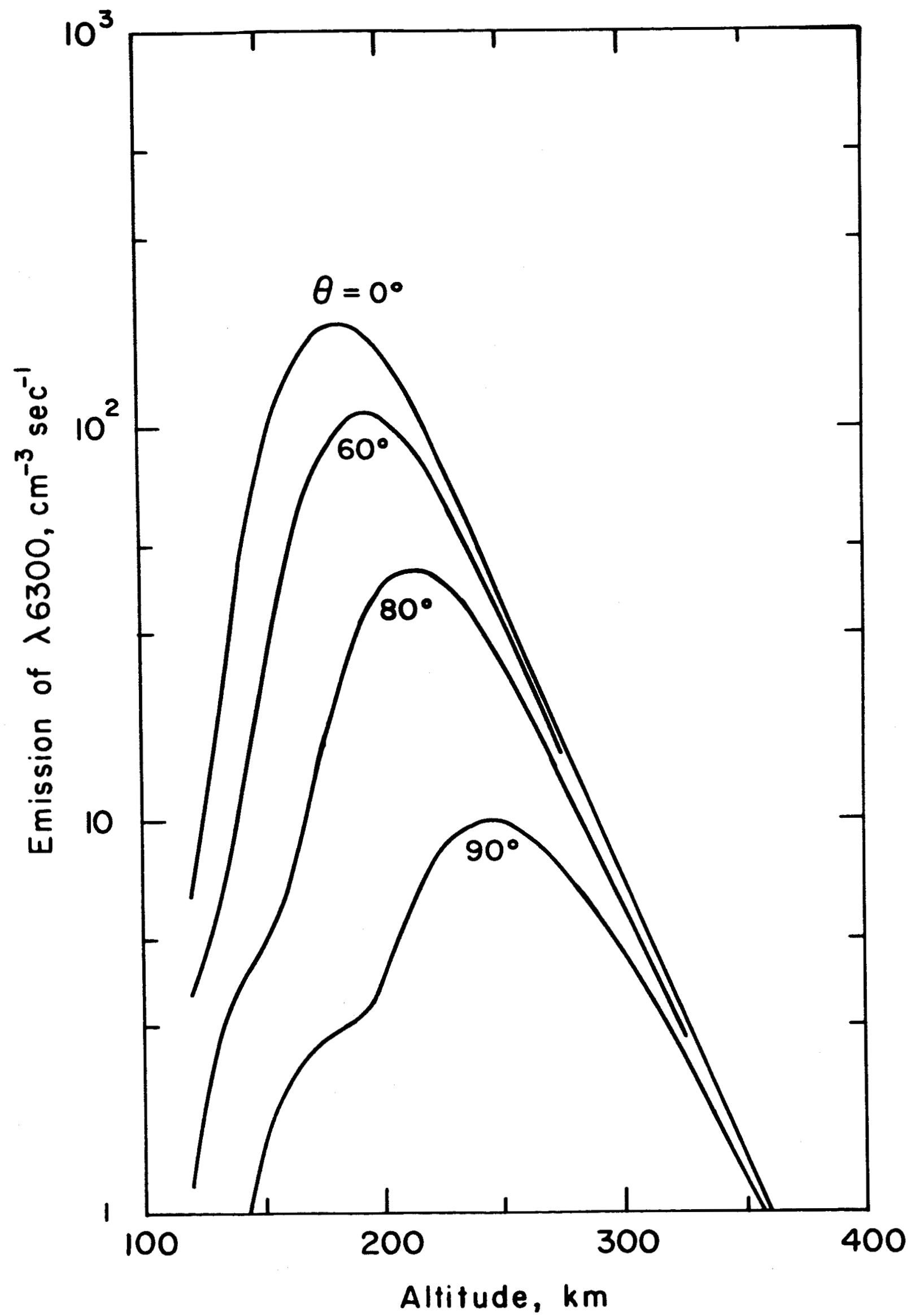

Fig. 9 


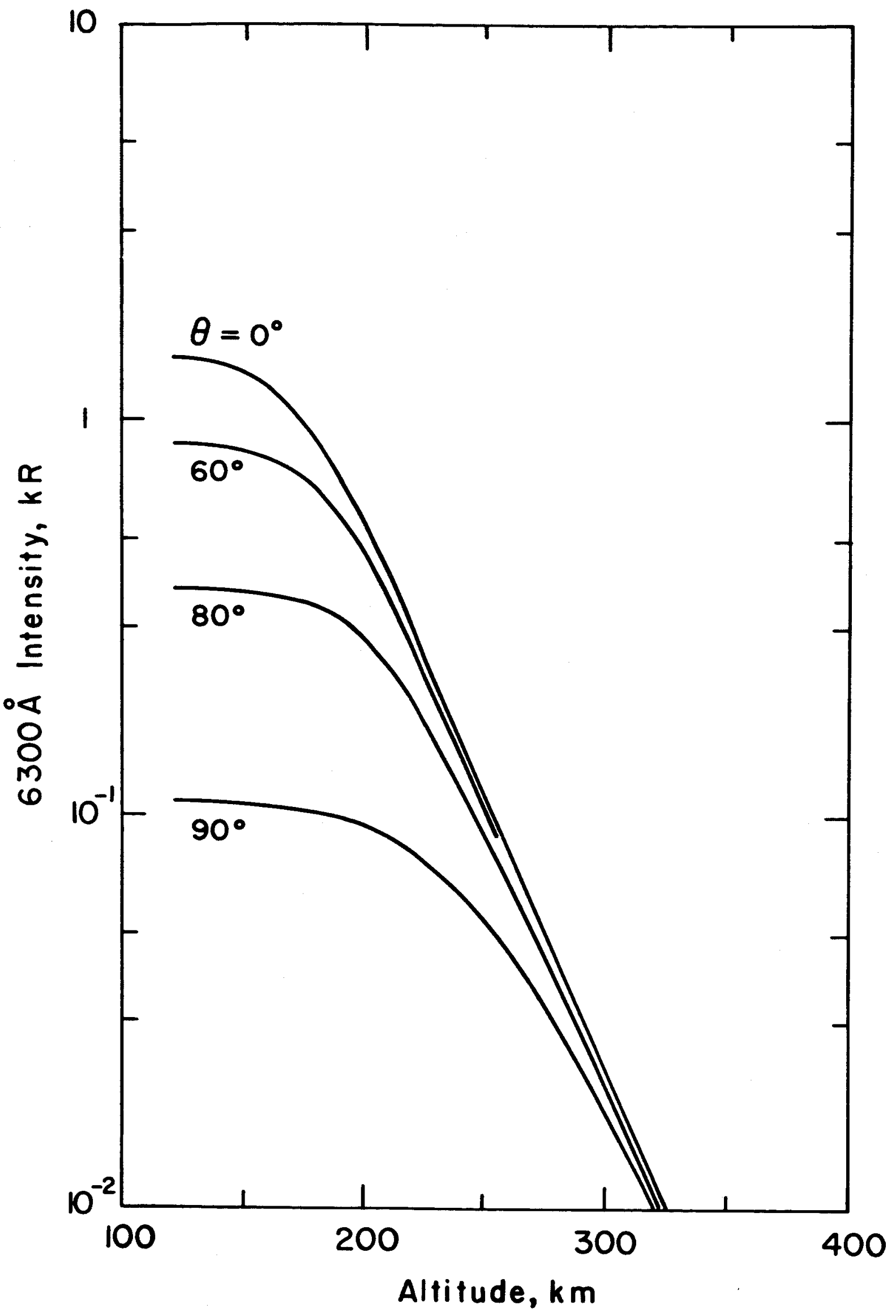

Fig. 10 


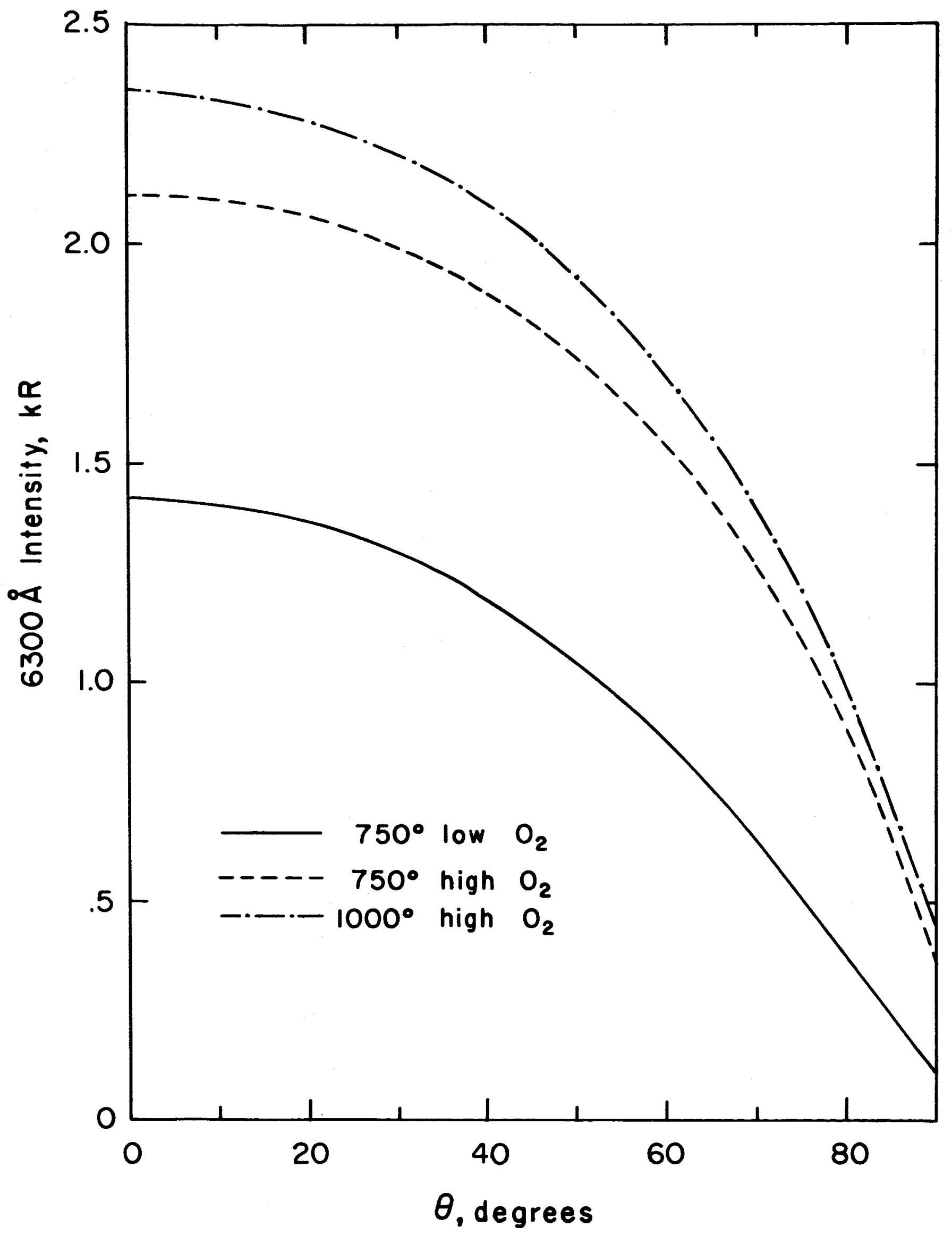

Fig. 11 


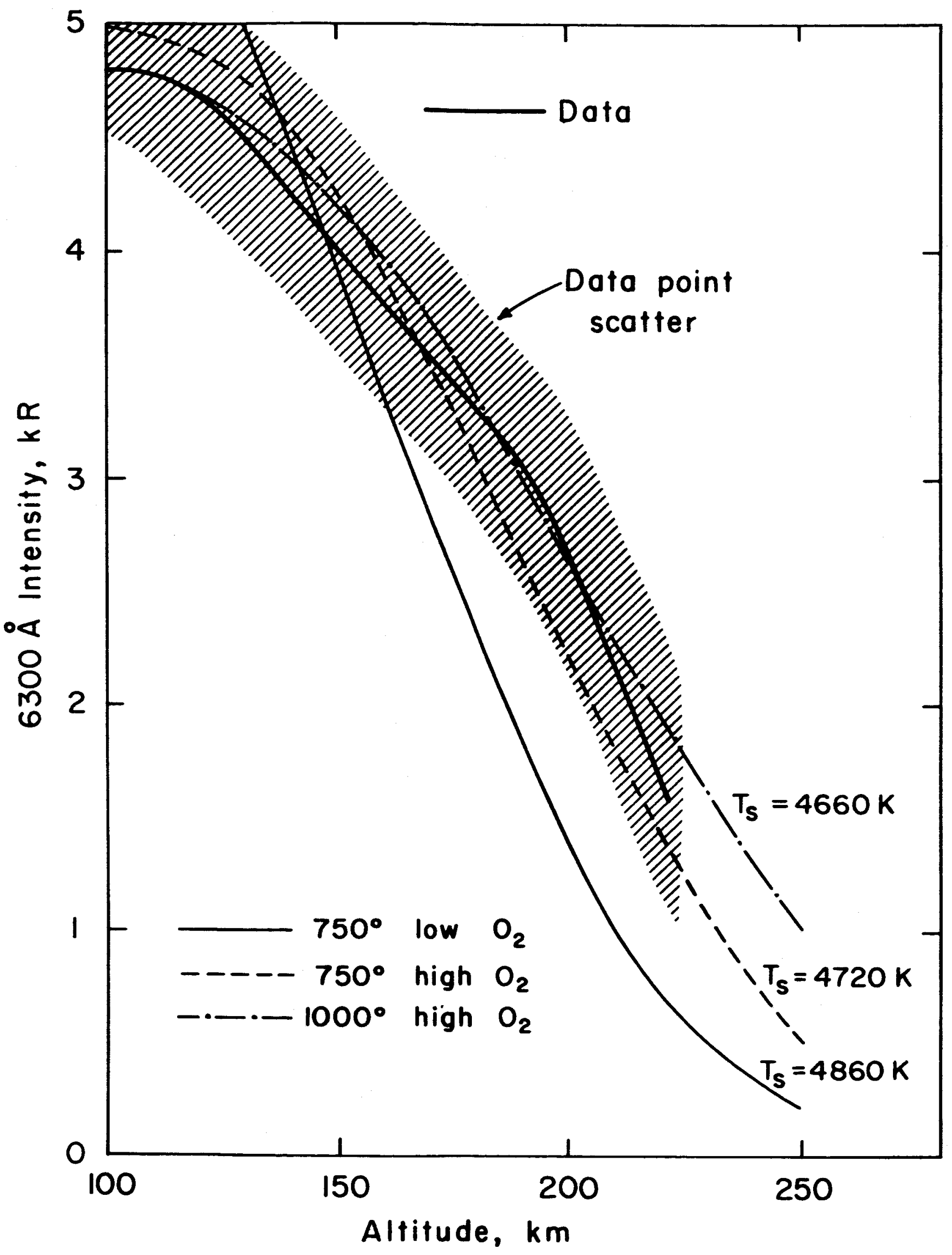

Fig. 12 


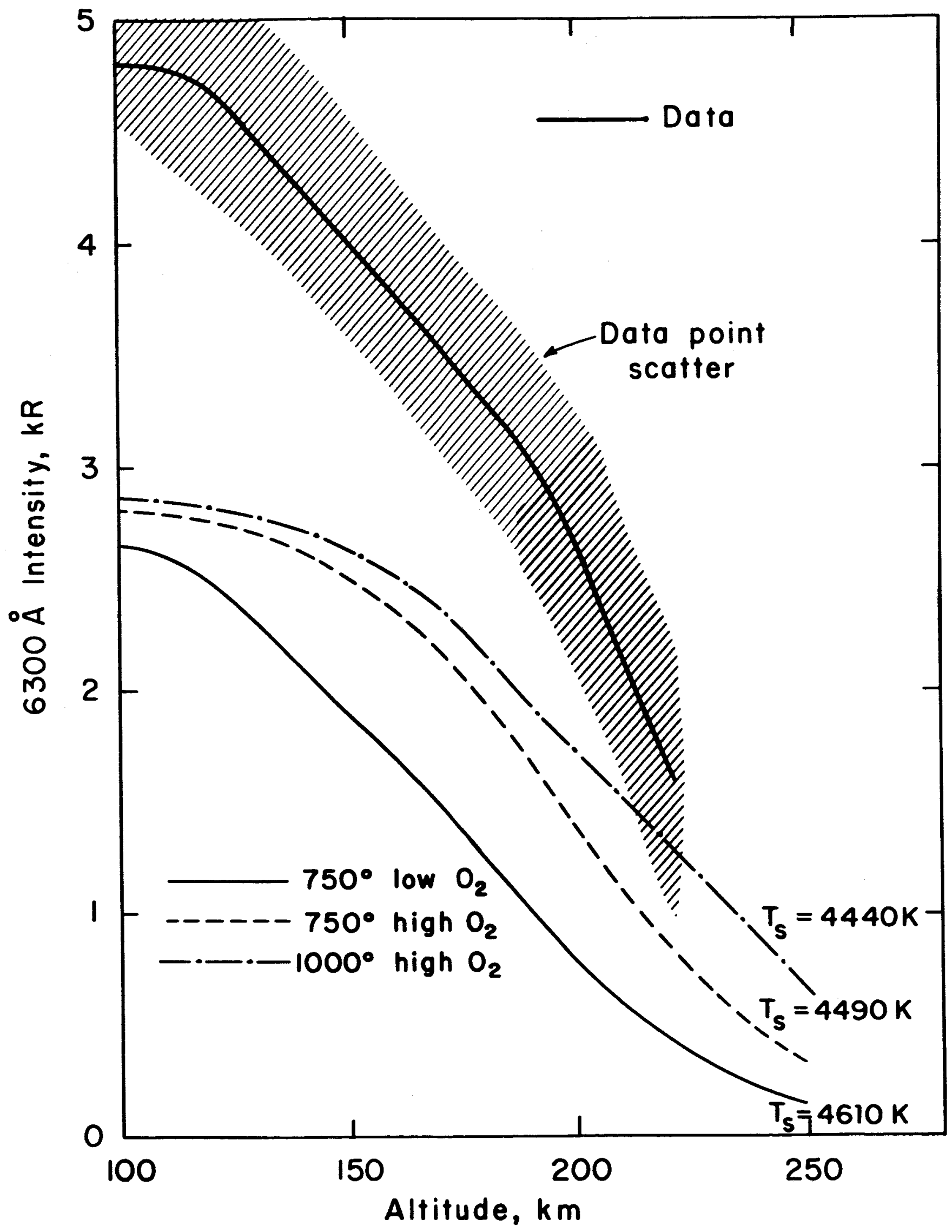

Fig. 13 


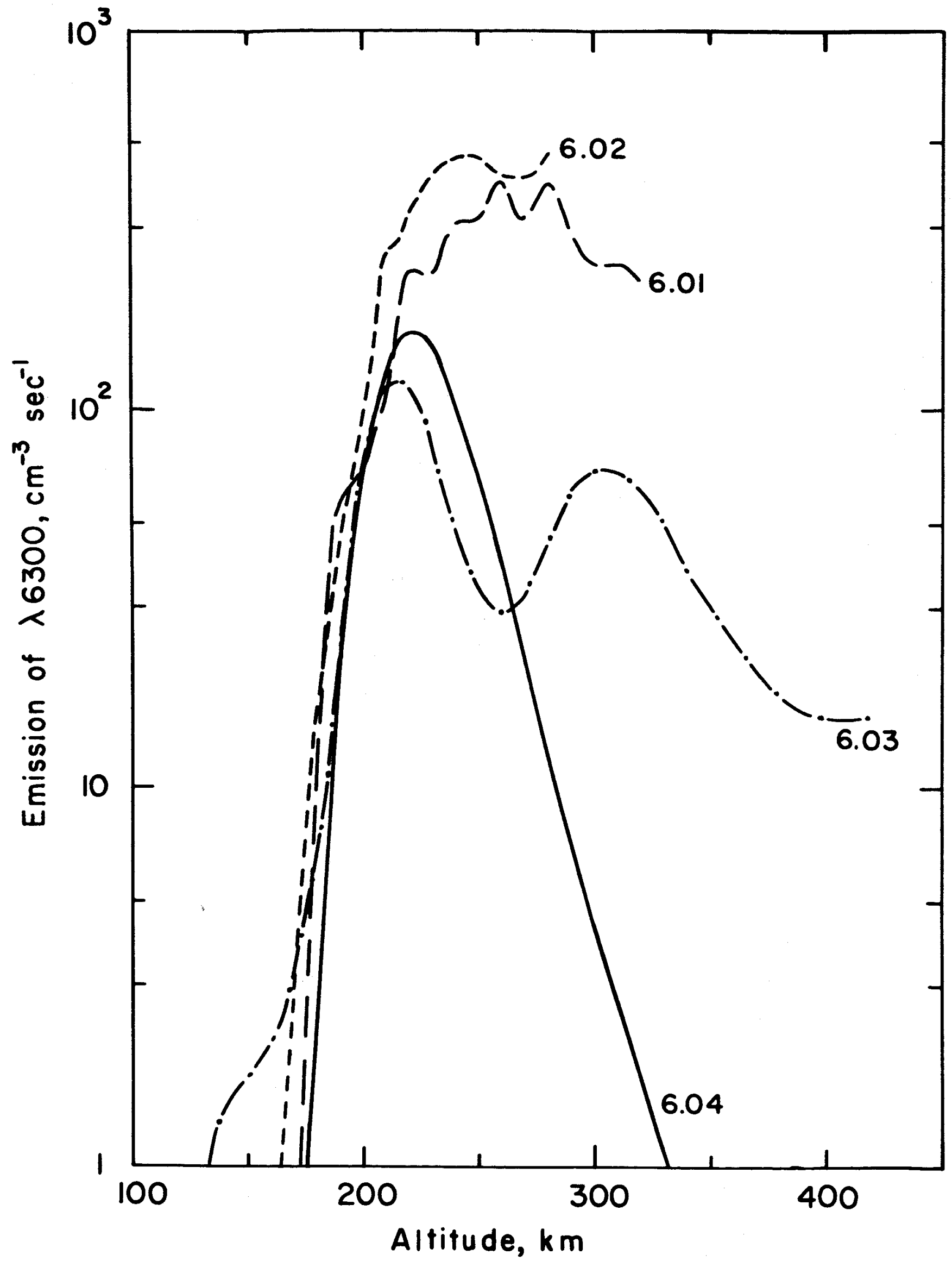

Fig. 14 


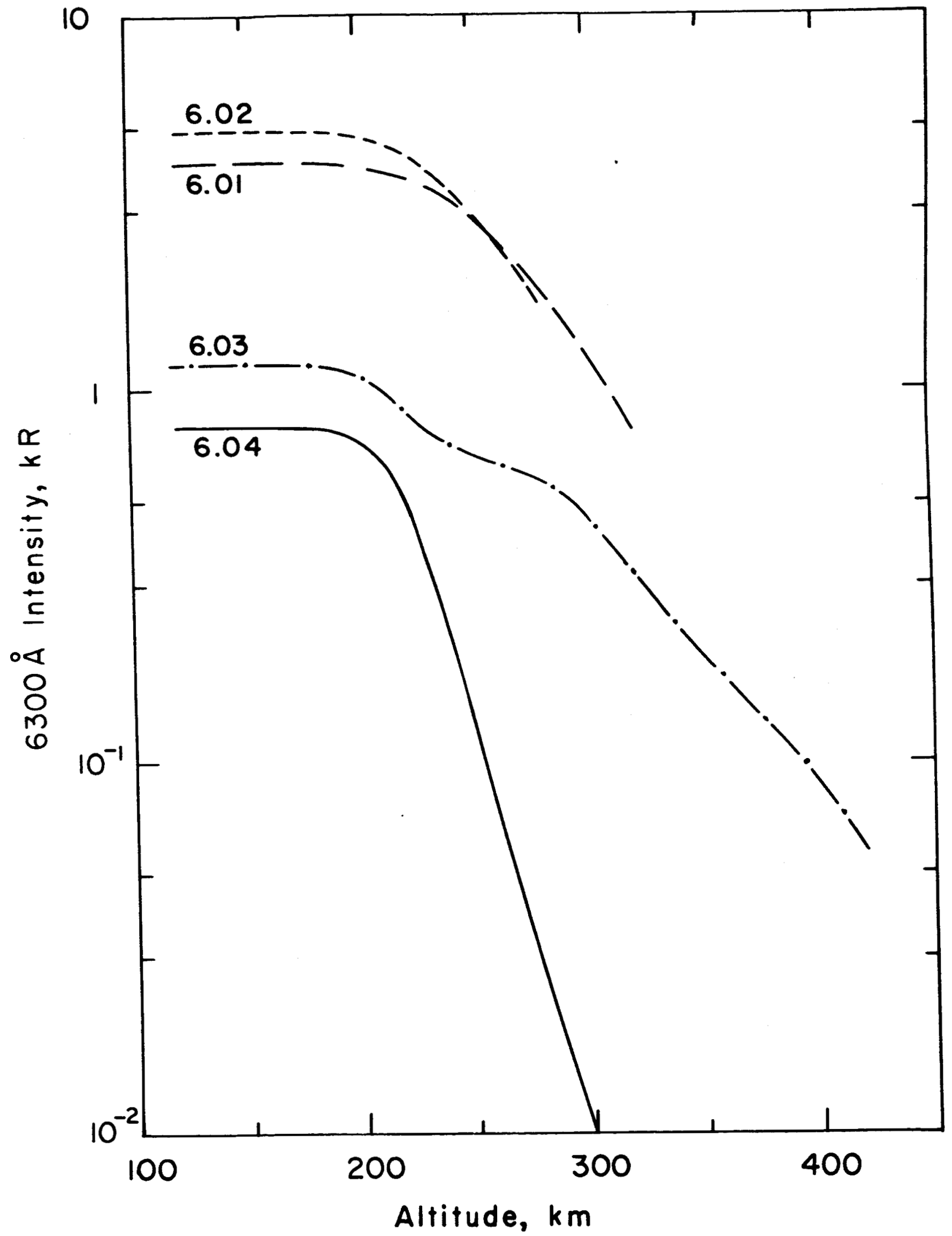

Fig. 15 


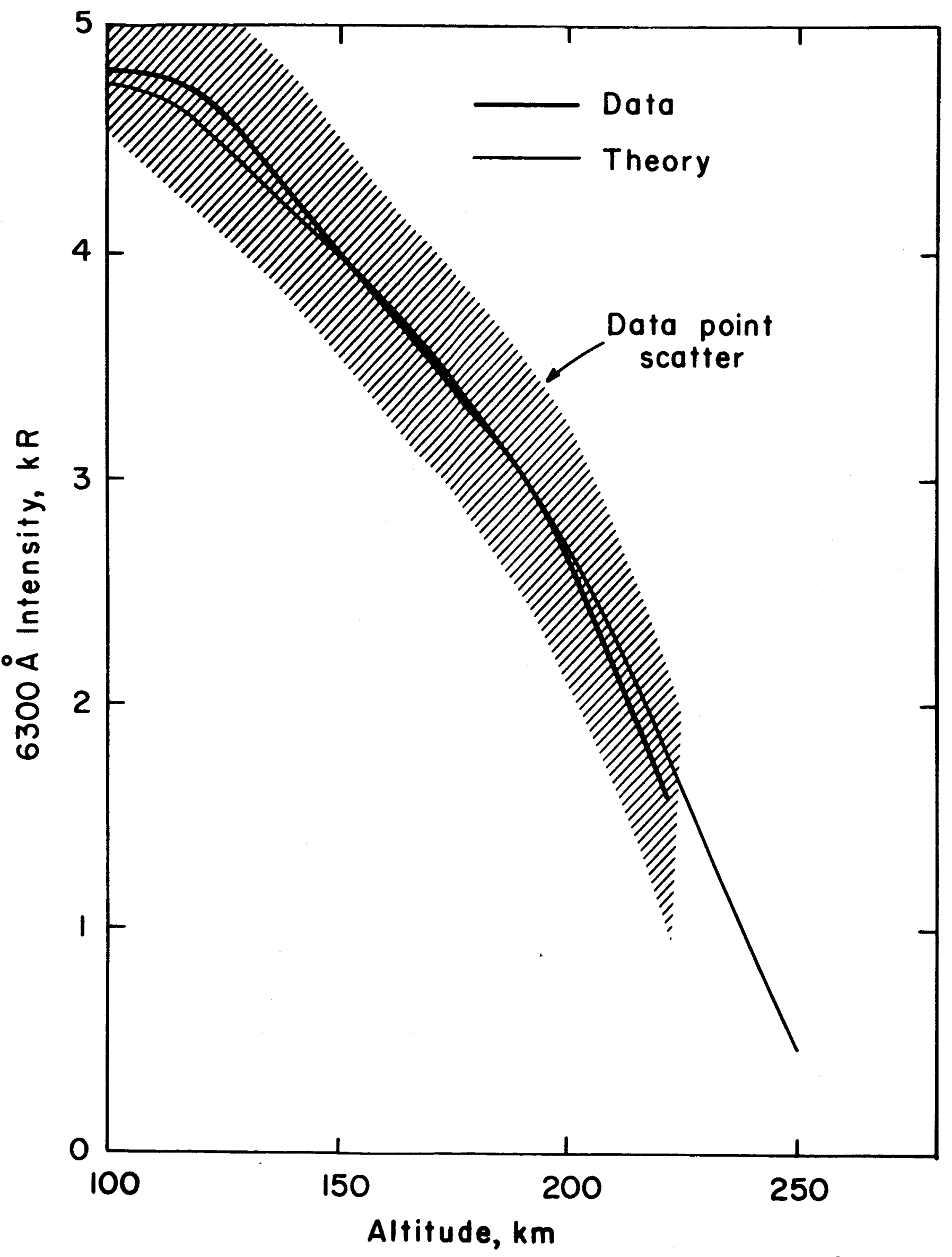

Fig. 16 